\title{
Bayesian inference and interpretation of centroid moment tensors of the 2016 Kumamoto earthquake sequence, Kyushu, Japan
}

\author{
Miroslav Hallo ${ }^{{ }^{*} \mathbb{D}}$, Kimiyuki Asano ${ }^{2}$ and František Gallovič ${ }^{1}$
}

\begin{abstract}
On April 16, 2016, Kumamoto prefecture in Kyushu region, Japan, was devastated by a shallow MJMA 7.3 earthquake. The series of foreshocks started by $M_{\text {JMA }} 6.5$ foreshock $28 \mathrm{~h}$ before the mainshock. They have originated in Hinagu fault zone intersecting the mainshock Futagawa fault zone; hence, the tectonic background for this earthquake sequence is rather complex. Here we infer centroid moment tensors (CMTs) for 11 events with $M_{\text {JMA }}$ between 4.8 and 6.5, using strong motion records of the K-NET, KiK-net and F-net networks. We use upgraded Bayesian full-waveform inversion code ISOLA-ObsPy, which takes into account uncertainty of the velocity model. Such an approach allows us to reliably assess uncertainty of the CMT parameters including the centroid position. The solutions show significant systematic spatial and temporal variations throughout the sequence. Foreshocks are right-lateral steeply dipping strike-slip events connected to the NE-SW shear zone. Those located close to the intersection of the Hinagu and Futagawa fault zones are dipping slightly to ESE, while those in the southern area are dipping to WNW. Contrarily, aftershocks are mostly normal dip-slip events, being related to the $\mathrm{N}-\mathrm{S}$ extensional tectonic regime. Most of the deviatoric moment tensors contain only minor CLVD component, which can be attributed to the velocity model uncertainty. Nevertheless, two of the CMTs involve a significant CLVD component, which may reflect complex rupture process. Decomposition of those moment tensors into two pure shear moment tensors suggests combined right-lateral strike-slip and normal dip-slip mechanisms, consistent with the tectonic settings of the intersection of the Hinagu and Futagawa fault zones.
\end{abstract}

Keywords: Tectonics, Inverse theory, Waveform source inversion, Centroid moment tensors, Strong motion data, 2016 Kumamoto sequence, Foreshocks and aftershocks, Futagawa and Hinagu faults

\section{Introduction}

The 2016 Kumamoto earthquake sequence started on April 14, 2016, with an $M_{\mathrm{IMA}} 6.5$ shallow earthquake in the central part of Kyushu, Japan (see Fig. 1). The seismic activity continued by weaker events, including $M_{\mathrm{IMA}} 5.8$ and $M_{\mathrm{JMA}} 6.4$ earthquakes $41 \mathrm{~min}$ and $2.6 \mathrm{~h}$ after the first shock, respectively. The mainshock of the sequence of $M_{\mathrm{JMA}} 7.3$ occurred on April 16, 2016 (01:25 of Japan

\footnotetext{
*Correspondence: hallo@karel.troja.mff.cuni.cz

${ }^{1}$ Faculty of Mathematics and Physics, Charles University, Prague, Czech Republic

Full list of author information is available at the end of the article
}

Standard Time), $28 \mathrm{~h}$ after the first earthquake (the yellow circle in Fig. 1). The mainshock generated destructive ground motions in the near-source region, causing severe damage and casualties. The following aftershocks had wide spatial distribution across the whole Kyushu with the strongest event of $M_{\mathrm{JMA}} 5.9$ that occurred 20 min after the mainshock. Increased seismic activity in the area was notable even 2 weeks after the first foreshock, and it was daily reported by the Japan Meteorological Agency (JMA). In the 2016 Kumamoto sequence, seven earthquakes reached or exceeded instrumental intensity $6-$ of the JMA intensity scale which consists of degrees $0,1,2$, $3,4,5-, 5+, 6-, 6+, 7$. 

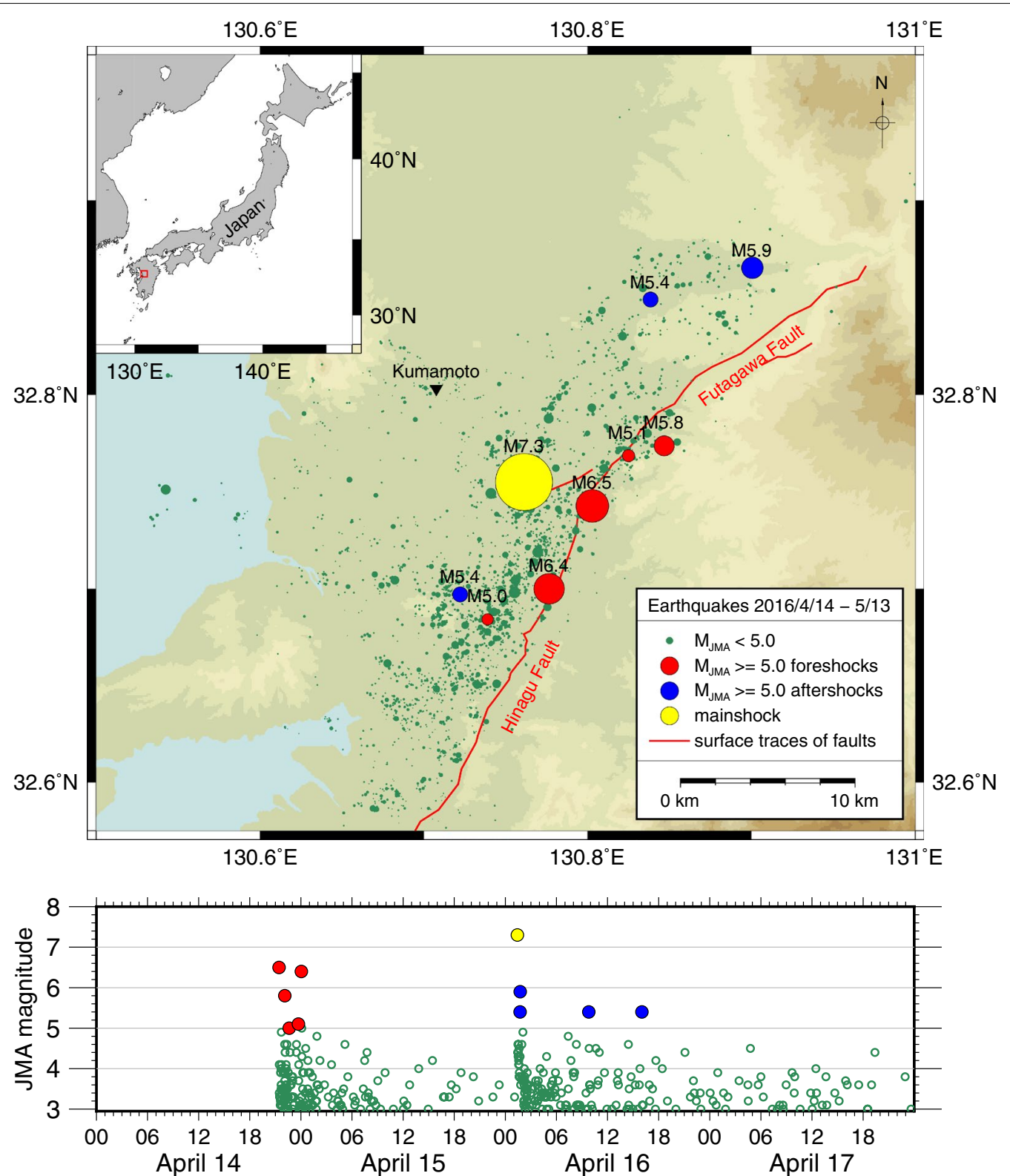

Fig. 1 Spatial and temporal distribution of the Kumamoto earthquake sequence; top panel—map of earthquake's locations inferred by Kato et al. (2016) for period April 14-May 13, 2016. The size of circles is proportional to the JMA magnitude of the events. Earthquakes with $M_{\mathrm{JMA}}$ magnitude higher than or equal to 5 are distinguish by color: foreshocks (red), mainshock (yellow) and aftershocks (blue); bottom panel—temporal evolution of the earthquakes from the map in top panel is showing period from April 14-April 17, 2016, when all events with $M_{\text {JMA }}$ magnitude higher than or equal to 5 occurred

This earthquake sequence occurred along the Futagawa-Hinagu fault system, which is one of the major active fault zones in Kyushu. This shear zone is considered to be western extension of the Median Tectonic Line (MTL), the largest tectonic line in southwestern Japan (e.g., Okada 1980; Kamata and Kodama 1994). The MTL is an active right-lateral strike-slip fault which originates at Honshu Island and transects whole Shikoku
Island. Extension of the MTL transects Kyushu at NESW direction, with evidence of right-lateral strike-slip and extensional movements (Kamata and Kodama 1994). An area in the central part of Kyushu, located north of the shear zone, is called the Beppu-Shimabara graben. It is characterized by many normal faults formed in the $\mathrm{N}-\mathrm{S}$ extensional stress regime. According to Kamata and Kodama (1999), this extension can be related to the effect 
of the Ryukyu Trench and convergence of the Philippine Sea slab, where it possibly induces seafloor spreading at the Okinawa Trough. The tectonic stress in Kyushu has large spatial heterogeneities (Matsumoto et al. 2015). At Kumamoto area, the minimum principal stress $\sigma_{3}$ (extension) is in the $\mathrm{N}-\mathrm{S}$ direction, and the maximum principal stress $\sigma_{1}$ has similar size as $\sigma_{2}$ (Matsumoto et al. 2015); therefore, strike-slip and also normal faults are expected under such stress regime.

The mainshock created more than 30-km-long system of co-seismic surface ruptures along the FutagawaHinagu fault system (e.g., Kumahara et al. 2016; Toda et al. 2016; Shirahama et al. 2016) terminating in the Aso volcano caldera (e.g., Lin et al. 2016). The surface coseismic ruptures were dominated by right-lateral strikeslips with a secondary normal faulting component. The normal faulting was dominant especially in the northeast part of the rupture zone (e.g., Toda et al. 2016). Finite source models for the mainshock were inverted from strong motion records (e.g., Asano and Iwata 2016; Kubo et al. 2016; Hao et al. 2017; Kobayashi et al. 2017; Yoshida et al. 2017). The inferred models suggest that the $M_{\mathrm{IMA}} 7.3$ event started near the intersection of the Futagawa and Hinagu faults by right-lateral strike-slip movement; then, the rupture propagated to the NE along the Futagawa fault as strike-slip with a normal faulting component. Finite source models and also static slip models from geodetic data (Himematsu and Furuya 2016; Fukahata and Hashimoto 2016) are consistent with field measurements of co-seismic surface ruptures. The source models introduce two or three segments of the mainshock rupture, but their physical relation to the foreshock ruptures remains unclear because of the complex tectonic settings of the intersection of the Futagawa and Hinagu faults.

This study focuses on the point source models of the significant foreshocks and aftershocks of the Kumamoto sequence. The centroid moment tensors (CMTs) for these events were inferred routinely by JMA and by National Research Institute for Earth Science and Disaster Resilience (NIED). However, these solutions are not supplemented by their uncertainty, which is required when trying to draw conclusions on the physical relations of ruptures in such case of complex tectonic settings. Here we infer CMTs of the significant foreshocks and aftershocks and their uncertainty by our novel fullwaveform inversion from strong motion data. The results are then interpreted in a seismotectonic framework.

\section{Methods}

\section{Problem formulation}

In the low-frequency point source approximation, the source is described by the centroid moment tensor (CMT, Aki and Richards 2002, pp. 49-52). The CMT consists of ten parameters: six moment tensor elements $M_{p q}$, location $\xi$ and time $\tau$. The centroid denotes to temporal and spatial center of the moment tensor density. Ground displacement $u_{n}$ at position $\mathbf{x}$ and time $t$ generated by CMT with the source time function $\Omega(t)$ is given for the $n$th component by

$$
u_{n}(\mathbf{x}, t)=M_{p q}(\boldsymbol{\xi}) \Omega(t-\tau) * H_{n p, q}(\mathbf{x}, \boldsymbol{\xi}, t),
$$

where star denotes convolution and $H_{n p, q}$ is the spatial derivative of Green's function (GF) representing response of the medium to a unite force. Eistein summation convention applies.

Kikuchi and Kanamori (1991) proposed to represent the moment tensor $M_{p q}(\mathrm{MT})$, for a given centroid position and time, by a linear combination of six elementary MTs defined therein. Then, discretized Eq. (1) can be expressed for a given source space-time position $i$ and a given function $\Omega(t)$ in a matrix form (Tarantola 2005, pp. 62-68),

$$
\boldsymbol{d}_{i}=\mathbf{G}_{i} \boldsymbol{m}_{i},
$$

where $\boldsymbol{d}_{i}$ is a vector of synthetic seismograms and $\boldsymbol{m}_{i}$ is a vector of six coefficients of the elementary MTs. $\mathbf{G}_{i}$ is a matrix of six columns composed of elementary seismograms, representing ground displacements caused by elementary MTs placed at position $i$. The problem is then linear for a given source space-time position (six elementary MT coefficients), whereas it is nonlinear for the other four parameters (location $\xi$ and time $\tau$ ).

\section{Bayesian inference of CMT}

We apply modification of the Bayesian full-waveform CMT inversion, ISOLA-ObsPy (Vackáŕ et al. 2017), which allows for reliable assessment of the solution uncertainty. In this method, a regular grid of four nonlinear CMT model parameters (location $\xi$ and time $\tau$ ) is considered. We assume one-column data vector $\boldsymbol{d}_{\text {obs }}$ characterized by Gaussian data errors with covariance matrix $\mathbf{C}_{D}$ (will be discussed in the next section). At a given space-time grid point $i$, assuming no prior information (i.e., infinite standard deviation) on the model parameters $\boldsymbol{m}_{i}$, the posterior probability density function (posterior PDF) for the MT is six-dimensional Gaussian function,

$$
\operatorname{PDF}_{i}\left(\boldsymbol{m}_{i}\right)=\frac{1}{c} \exp \left(-\frac{1}{2}\left(\boldsymbol{d}_{\mathrm{obs}}-\mathbf{G}_{i} \boldsymbol{m}_{i}\right)^{\mathrm{T}} \mathbf{C}_{\mathbf{D}}^{-1}\left(\boldsymbol{d}_{\mathrm{obs}}-\mathbf{G}_{i} \boldsymbol{m}_{i}\right)\right) .
$$

Parameter $c$ is a constant normalizing the total tendimensional PDF to unity. Note that the term including prior information on the model parameters (Tarantola 2005, eq. 1.104) is not present in Eq. (3) as it is equal to 1.

After simple algebra, Eq. (3) can be equivalently written as 


$$
\begin{aligned}
& \operatorname{PDF}_{i}\left(\boldsymbol{m}_{i}\right) \\
& =\frac{1}{c} \exp \left(-\frac{1}{2}\left(\boldsymbol{m}_{i}-\tilde{\boldsymbol{m}}_{i}\right)^{\mathrm{T}} \tilde{\mathbf{C}}_{i}^{\mathbf{M}-1}\left(\boldsymbol{m}_{i}-\tilde{\boldsymbol{m}}_{i}\right)-\frac{1}{2} \mathcal{L}_{i}\right) \\
& \text { with } \\
& \mathcal{L}_{i}=\left(\boldsymbol{d}_{\mathrm{obs}}-\mathbf{G}_{i} \tilde{\boldsymbol{m}}_{i}\right)^{\mathrm{T}} \mathbf{C}_{\mathbf{D}}^{-1}\left(\boldsymbol{d}_{\mathrm{obs}}-\mathbf{G}_{i} \tilde{\boldsymbol{m}}_{i}\right), \\
& \tilde{\boldsymbol{m}}_{i}=\left(\mathbf{G}_{i}^{\mathrm{T}} \mathbf{C}_{\mathbf{D}}^{-1} \mathbf{G}_{i}\right)^{-1}\left(\mathbf{G}_{i}^{\mathrm{T}} \mathbf{C}_{\mathbf{D}}^{-1} \boldsymbol{d}_{\mathrm{obs}}\right), \quad \text { and } \\
& \tilde{\mathbf{C}}_{i}^{\mathbf{M}}=\left(\mathbf{G}_{i}^{\mathrm{T}} \mathbf{C}_{\mathbf{D}}^{-1} \mathbf{G}_{i}\right)^{-1} .
\end{aligned}
$$

In Eq. (6), $\tilde{\boldsymbol{m}}_{i}$ corresponds to the least squares solution of the six model parameters with misfit $\mathcal{L}_{i}$ from Eq. (5) (Tarantola 2005, eq. 3.40). The associated uncertainties (of the least squares solution $\tilde{\boldsymbol{m}}_{i}$ ) are described by the posterior model covariance matrix $\tilde{\mathbf{C}}_{i}^{\mathbf{M}}$ given in Eq. (7) (Tarantola 2005, Eq. 3.41).

The role of the data covariance matrix $\mathbf{C}_{\mathbf{D}}$ in the inversion is apparent in definition of the misfit function. In MT inversion without considering $\mathbf{C}_{\mathrm{D}}$, the misfit function is difference (residuals) between the recorded data $\boldsymbol{d}_{\text {obs }}$ and synthetics $\boldsymbol{d}_{i}$. If the covariance matrix $\mathbf{C}_{\mathrm{D}}$ is used, the misfit function is given by so-called standardized residuals (Dettmer et al. 2014), i.e., waveforms multiplied by the triangular matrix $\mathbf{W}$ from the Cholesky decomposition of $\mathrm{C}_{\mathrm{D}}$

$$
\mathbf{C}_{\mathbf{D}}^{-1}=\mathbf{W}^{\mathrm{T}} \mathbf{W} \text {. }
$$

The variance reduction, a parameter evaluating solution fit to measured data in the grid point $i$, is then given by

$$
\mathrm{VR}_{i}=\left(1-\frac{\left\|\mathbf{W}^{\mathrm{T}} \boldsymbol{d}_{\mathrm{obs}}-\mathbf{W}^{\mathrm{T}} \boldsymbol{d}_{\boldsymbol{i}}\right\|^{2}}{\left\|\mathbf{W}^{\mathrm{T}} \boldsymbol{d}_{\mathrm{obs}}\right\|^{2}}\right) \cdot 100 \% .
$$

The normalizing constant $c$ from Eq. (3) can be obtained by integration over all the ten CMT parameters. In our case, we integrate over the space-time grid points (Vackář et al. 2017),

$$
\begin{aligned}
1 & =\sum_{i} \mathrm{~d} V_{i} \int \operatorname{PDF}_{i}\left(\boldsymbol{m}_{i}\right) \mathrm{d} \boldsymbol{m}_{i} \\
& =\sum_{i} \frac{1}{c} \sqrt{(2 \pi)^{6} \operatorname{det} \tilde{\mathbf{C}}_{i}^{\mathbf{M}}} \exp \left(-\frac{1}{2} \mathcal{L}_{i}\right) \mathrm{d} V_{i} \\
& =\sum_{i} a_{i},
\end{aligned}
$$

where the term $\mathrm{d} V_{i}$ is the product of grid steps of all the four nonlinear model parameters (i.e., the space and time discretization steps). The value $a_{i}$ is an integral of $\mathrm{PDF}_{i}$ at the given space-time grid point. It depends on the most likely solution misfit $\mathcal{L}_{i}$ and the determinant of the posterior covariance matrix of model parameters $\tilde{\mathbf{C}}_{i}^{\mathbf{M}}$, in particular space-time grid point. It thus carries information about the quality of the least squares solution in particular grid point.

Vackář et al. (2017) propose to inspect posterior PDF of any CMT parameters by generating set of random possible solutions from the total ten-dimensional posterior PDF. This can be achieved by drawing $a_{i}$ random samples at each space-time grid point from the multivariate normal distribution specified by $\tilde{\boldsymbol{m}}_{i}$ and $\tilde{\mathbf{C}}_{i}^{\mathbf{M}}$. From such ensemble, it is then possible to statistically assess uncertainty of any CMT parameter, including those that are not directly inverted for, but can be derived from the MT components (e.g., strike angle, dip angle, rake angle and DC component percentage).

\section{Accounting for the uncertainty of the velocity structure}

The reliability of the assessment of the solution uncertainty by this Bayesian framework depends on the assessment of the data and modeling errors. The data errors (i.e., the instrumental and ambient noise) are typically negligible when dealing with larger events, as in our present application. We avoid using data with rare instrumental artifacts (e.g., Zahradník and Plešinger 2010). The solution uncertainty is then dominated by modeling errors governed by the uncertainty of the GFs due to the inaccuracy of the crustal model considered. We include the modeling errors in covariance matrix $\mathbf{C}_{\mathbf{D}}$ following approach by Hallo and Gallovič (2016). They compose $\mathrm{C}_{\mathrm{D}}$ from so-called stationarized approximate covariance functions defined by

$$
\overline{\operatorname{cov}}(\varphi)=\frac{1}{T}\left[r(\varphi)-\wedge_{2 L}(\varphi) * r(\varphi)\right],
$$

where $r(\varphi)$ is autocorrelation of the observed seismogram as a function of time lag $\varphi, T$ is duration of the dominant part of the signal, star is convolution and $\wedge_{2 L}(\varphi)$ is a triangle function of unit area centered around zero with duration $2 L$. Since Eq. (11) is stationary (i.e., depending only on time lag $\varphi$ ), the respective covariance matrix has Toeplitz structure (diagonal constant). Parameter $L$ generally depends on the source-receiver distance, frequency range and considered uncertainty of the velocity model. Hallo and Gallovič (2016) tested the performance of such covariance matrices by means of numerous MT inversions with synthetic data generated in randomly perturbed velocity models. The posterior model covariance matrix from inversion using $\overline{\mathrm{COV}}$ (Eq. (11)) was therein shown to reliably reflect the simulated uncertainty of the inferred MTs.

In the present multi-station and multi-component inversion, data covariance matrix $\mathbf{C}_{\mathbf{D}}$ has block structure. 
The covariance matrices for the individual waveforms are arranged along the diagonal, while off-diagonal blocks (cross-covariances) are neglected and hence set to zeros. A station-specific water level was added to the diagonal to preserve the covariance matrix invertible. As the water level, we use $10 \%$ of the maximum variance from all the three station components. The parameters $L$ from Eq. (11) were determined based on relation introduced by Hallo and Gallovič (2016) in a similar inversion setting

$$
L=\frac{\left|\mathbf{x}-\mathbf{x}_{\text {epic }}\right|}{25[\mathrm{~km} / \mathrm{s}]},
$$

where $\left|\mathbf{x}-\mathbf{x}_{\text {epic }}\right|$ denotes horizontal distance between the station and epicenter in kilometers. Such an estimate is found suitable for velocity model uncertainty of $10 \%$. The duration of the dominant part of the signal $T$ was set to $15 \mathrm{~s}$ for all stations and events.

\section{Application to the 2016 Kumamoto sequence}

We infer CMTs of 11 significant earthquakes with $M_{\text {JMA }}$ magnitude in range of 4.8-6.5 (see Table 1 for list of the events). The set consists of all foreshocks and aftershocks with $M_{\mathrm{JMA}}$ magnitude higher than or equal to 5 (denoted by red and blue circles in Fig. 1), and two aftershocks with $M_{\mathrm{IMA}}$ magnitude 4.9 and 4.8 . The mainshock itself was omitted from the analysis as it has rather complex earthquake source rupture process that was studied in detail in other studies (e.g., Asano and Iwata 2016; Kubo et al. 2016; Kobayashi et al. 2017).

\section{Data selection and processing}

We use three-component waveforms recorded by the K-NET, KiK-net and F-net networks, operated by National Research Institute for Earth Science and Disaster Resilience (NIED), in the distances of $10-60 \mathrm{~km}$ from the epicenter (depending on the particular event). The stations are selected based on azimuthal coverage, distance and sufficient signal-to-noise ratio in the low-frequency range. Stations located too close to the epicenter are excluded to comply with the point source approximation, i.e., to avoid station distances for which GFs along the fault differ significantly. Original acceleration data (K-NET and KiK-net) and strong motion velocity data corrected for the instrument response (F-net) are filtered by a bandpass filter and integrated into displacements (the K-NET and KiK-net accelerographs have flat transfer function in our target frequency range). The filter corner frequencies are determined empirically by manual inspection and processing of the waveforms (see Table 1). In general, the high-pass filter corner frequency is as low as possible in terms of signal-to-noise ratio. The low-pass filter corner frequency is limited by corner frequency of the particular earthquake. Waveform data are downsampled after the filtration and integration to the sampling frequency $0.6-1.3 \mathrm{~Hz}$, based on the low-pass filter corner frequency, in order to reduce computational demands.

\section{Velocity model}

GFs are computed by the discrete wavenumber method (Bouchon 1981) in 1D velocity model consisting of homogenous layers. The model is prepared from the 3D Japan Integrated Velocity Structure Model (Koketsu et al. 2012) as a horizontal average over area of $40 \times 40 \mathrm{~km}$ around mainshock epicenter. The horizontal average is calculated for a dense set of depths (smooth model in Fig. 2a) and then divided into homogenous layers preserving the vertical travel times within layers (layered model in Fig. 2a). Figure $2 \mathrm{~b}$ shows maximal deviation of the 1D model from the original 3D model (maximal lateral heterogeneities which are not included in the 1D

Table 1 List of processed earthquakes from the Kumamoto sequence

\begin{tabular}{|c|c|c|c|c|c|c|c|c|c|}
\hline \multicolumn{4}{|c|}{ Event } & \multicolumn{3}{|c|}{ JMA hypocentre location } & \multicolumn{2}{|c|}{ Filter corner frequency } & \multirow{2}{*}{$\begin{array}{l}\text { Number of used } \\
\text { stations }\end{array}$} \\
\hline No. & $M_{\mathrm{JMA}}$ & Date & Time (JST) & Lat. & Lon. & Depth (km) & High pass $(\mathrm{Hz})$ & Low pass $(\mathrm{Hz})$ & \\
\hline 1 & 6.5 & 2016/4/14 & $21: 26: 35$ & 32.74 & 130.81 & 11 & 0.03 & 0.07 & 12 \\
\hline 2 & 6.4 & $2016 / 4 / 15$ & 00:03:47 & 32.70 & 130.78 & 7 & 0.03 & 0.08 & 12 \\
\hline 3 & 5.9 & 2016/4/16 & $01: 46: 56$ & 32.86 & 130.90 & 11 & 0.04 & 0.07 & 11 \\
\hline 4 & 5.8 & 2016/4/14 & $22: 07: 35$ & 32.77 & 130.85 & 8 & 0.08 & 0.14 & 12 \\
\hline 5 & 5.4 & 2016/4/16 & 01:44:06 & 32.75 & 130.76 & 15 & 0.15 & 0.20 & 10 \\
\hline 6 & 5.4 & 2016/4/16 & 09:48:32 & 32.85 & 130.84 & 16 & 0.08 & 0.15 & 13 \\
\hline 7 & 5.4 & 2016/4/16 & 16:02:01 & 32.70 & 130.72 & 12 & 0.08 & 0.15 & 11 \\
\hline 8 & 5.1 & 2016/4/14 & $23: 43: 41$ & 32.77 & 130.83 & 14 & 0.08 & 0.14 & 10 \\
\hline 9 & 5.0 & $2016 / 4 / 14$ & $22: 38: 43$ & 32.68 & 130.74 & 11 & 0.09 & 0.15 & 10 \\
\hline 10 & 4.9 & 2016/4/16 & 02:04:11 & 32.74 & 130.74 & 12 & 0.11 & 0.15 & 8 \\
\hline 11 & 4.8 & $2016 / 4 / 16$ & $07: 23: 55$ & 32.79 & 130.77 & 12 & 0.12 & 0.16 & 9 \\
\hline
\end{tabular}



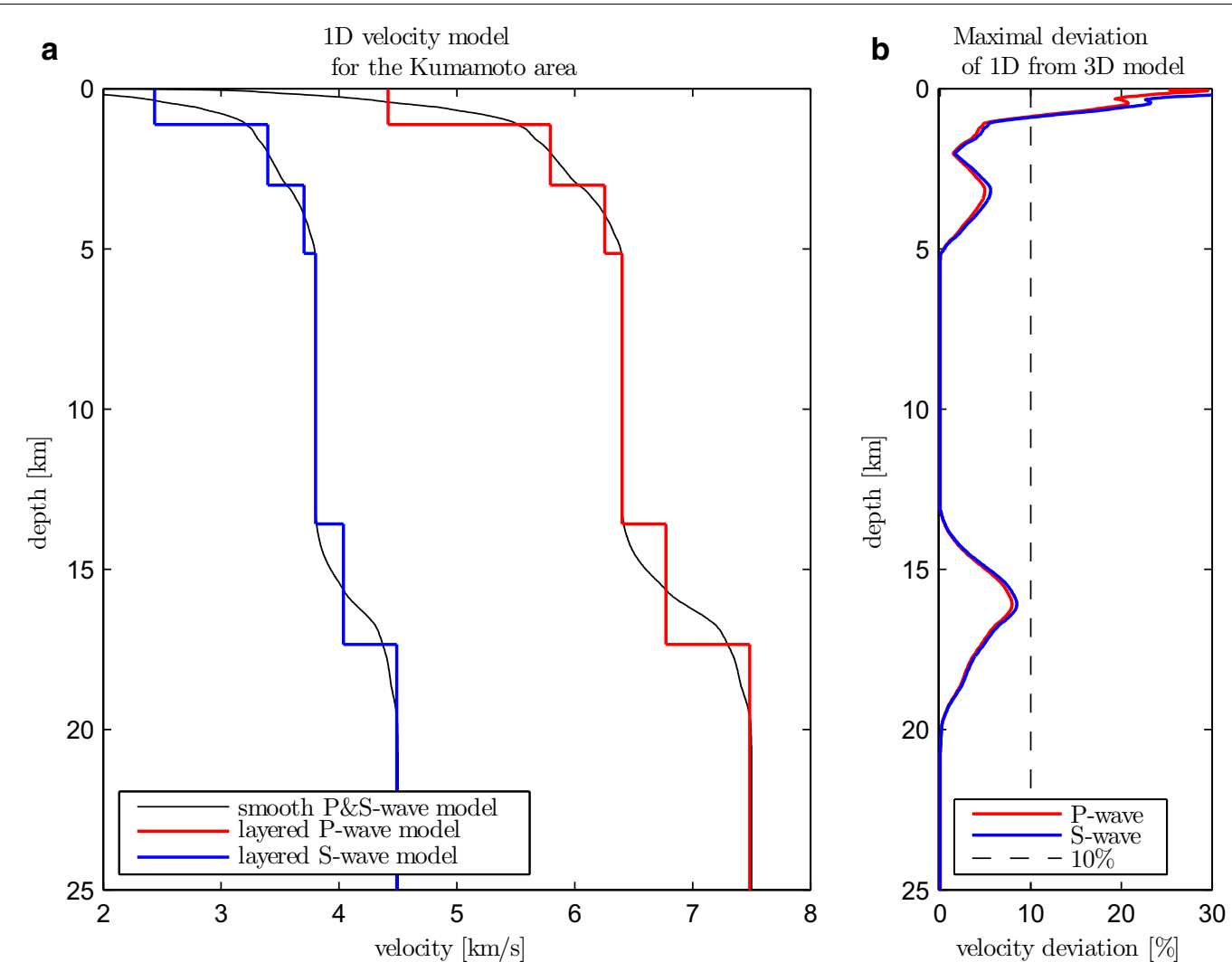

Fig. 2 a 1D velocity model of the Kumamoto area determined from the 3D Japan Integrated Velocity Structure Model (Koketsu et al. 2012) and b maximal horizontal deviation of the velocities of the determined 1D model from the original 3D model

model). These velocity variations are less than $10 \%$ for depths larger than $1 \mathrm{~km}$. The shallow layers show higher lateral heterogeneities, but they do not significantly affect the inversion using much longer wavelengths for sources at depths of Kumamoto earthquakes.

\section{Application details}

The CMT inversion strategy consists of the following processing steps:

1. Inference of full CMT, including isotropic component, is performed by inversion from extended set of stations without considering any model or data uncertainty. At this stage, we consider a rough grid of space-time grid points in the search of the nonlinear parameters, with regular grid steps of $1.4 \mathrm{~km}$ in all three coordinate directions within $16 \mathrm{~km}$ around the hypocenter reported by JMA. Time grid covers $0-4 \mathrm{~s}$ after the hypocenter time with regular time grid steps of about $0.3-0.1 \mathrm{~s}$ (depending on the particular event).

2. We manually inspect the best fit of the synthetic and measured waveforms to reveal stations with unusable signal. The proposed Bayesian inference is intended to deal with unknown velocity model perturbations which are close to the $1 \mathrm{D}$ velocity model, but it cannot correct for missing velocity structures or other systematical errors in the waveform data. Hence, stations with very poor fit are excluded from the next step of the processing. Mostly, it is the case of very distant stations or receivers located in the coastal area of the Ariake Sea. The final number of used stations is shown in Table 1.

3. We perform the Bayesian inference of CMT taking into account velocity model uncertainty of $10 \%$. Here we consider a denser grid in the search of the nonlinear parameters with regular grid steps about $0.2-0.5 \mathrm{~km}$ in all three coordinate directions within 3-5 $\mathrm{km}$ around the CMT location inverted in the first step. Time grid covers $0-4 \mathrm{~s}$ after the hypocenter time with regular time grid steps of about $0.1 \mathrm{~s}$. Since isotropic component of MT was negligible in all cases, we conserve it at $0 \%$.

As the ensemble of acceptable solutions, we generate 1000 random possible solutions drawn from the ten-dimensional posterior PDF. The resulting MTs are decomposed into combination of double-couple (DC) 
and compensated linear vector dipole (CLVD) sources. Marginal PDFs of selected CMT parameters (marginal histograms) are fitted with Gaussian function defined by its mean and standard deviation $\sigma$. We consider $2 \sigma$ as the estimate of the uncertainty covering half-width of a $95 \%$ confidence interval of the normal distribution.

As examples of the application, we depict three selected CMT inversions in Figs. 3, 4 and 5. Figure 3 shows the CMT inversion of the strongest $M_{\mathrm{IMA}} 6.5$ foreshock (event No. 1) in terms of the network settings, the best fit of the standardized waveforms at all stations and the best beach-ball solution with uncertainty (see the figure caption). Figure 4 shows the same, but for the $M_{\mathrm{JMA}} 5.8$ foreshock (event No. 4), which is performed from the same set of stations as for the previous event. The solution has a high variance reduction and high DC content. The example in Fig. 5 corresponds to the $M_{\mathrm{IMA}} 5.4$ aftershock (event No. 7), which is characterized by high variance reduction and high (significant) CLVD content.

\section{Solutions of the CMT inversion}

Parameters of the inferred CMT solutions from the Kumamoto sequence together with their uncertainty are compiled in Table 2. The beach-ball representations of these CMTs are shown in Fig. 6 together with comparison from the JMA and NIED solutions (the comparison is discussed later). Additionally, the inferred most likely solutions are listed in Appendix 1 in terms of the MT components.

The variance reduction defined by Eq. (9) is high for most events; nevertheless, solutions for two events (Nos. 1 and 5) have it below 50\%. In the case of event No. 5 , the raw waveforms seem corrupted at very low frequencies; hence, slightly higher frequency band was used (see Table 1), which most likely causes the fit deterioration. The event No. 1 is the strongest foreshock which was shown to consist of two spatially separated asperities by Asano and Iwata (2016). Our inferred CMT solution is located between the asperities; nevertheless, the lower variance reduction is likely related to the fact that the distance of the nearest station is at the margin of applicability of the point source approximation $(20 \mathrm{~km}$ CMTto-site distance vs. $12 \mathrm{~km}$ length of the fault).

The uncertainties of the CMT locations are up to $1.5 \mathrm{~km}$ in both horizontal and vertical directions for all events. Moreover, events with high variance reduction have CMT location uncertainty as small as $0.6 \mathrm{~km}$. Table 2 documents that the percentage of the DC source content has spans from 64 to $98 \%$. In most cases, it is characterized by large uncertainty including also possibility of pure shear (DC 100\%), and hence, the presence of CLVD component cannot be proved (but also disproved) for most of the inferred CMT solutions. The exceptions are events No. 1, 3 and 7 whose admissible DC values do not exceed $90 \%$ even taking the uncertainty into account $(64+24,67+16$ and $75+8 \%$, respectively; see Table 2$)$. Hence, we consider these events as having a significant CLVD component. Moreover, event No. 7 has the highest variance reduction in all the events, and hence, we consider its CLVD component particularly well constrained.

\section{CMTs with significant CLVD component}

The inferred CMT solutions of the Kumamoto earthquakes were decomposed into combination of DC and CLVD sources. While the DC component has direct physical interpretation in terms of shear faulting, the CLVD component points to possible complexity of the faulting (e.g., Frohlich 1994). Indeed, the non-DC MT can be decomposed into a combination of two or more DC sources. Unfortunately, such decomposition is mathematically non-unique, which brings difficulties to interpretation, and requires some physical constraint.

\section{Non-DC MT decomposition into two DC MTs}

Jost and Herrmann (1989) decompose a MT with CLVD component into so-called major and minor DC sources preserving directions of the three principal stress axes $\left(P_{-}\right.$, $T$ - and $N$-axis). Note that despite the fact that the principal stress axes directions are preserved, the axes types may generally interchange. Let us assume absolute values of non-DC MT eigenvalues $\left|\lambda_{1}\right| \geq\left|\lambda_{2}\right| \geq\left|\lambda_{3}\right|$ with respective eigenvectors $\boldsymbol{v}_{1}, \boldsymbol{v}_{2}$ and $\boldsymbol{v}_{3}(1 \times 3$ row vectors $)$. We use definition of the major and minor DC moment tensors as

$$
\begin{aligned}
& \mathbf{M T}_{\text {major }}=\lambda_{2}\left(-\boldsymbol{v}_{1}^{\mathrm{T}} \boldsymbol{v}_{1}+\boldsymbol{v}_{2}^{\mathrm{T}} \boldsymbol{v}_{2}\right), \quad \text { and } \\
& \mathbf{M T}_{\text {minor }}=\lambda_{3}\left(-\boldsymbol{v}_{1}^{\mathrm{T}} \boldsymbol{v}_{1}+\boldsymbol{v}_{3}^{\mathrm{T}} \boldsymbol{v}_{3}\right) .
\end{aligned}
$$

In such formulation, the major MT is the best DC approximation of a shear seismic source, under additional assumption of preserved main principal stress axis (axis with $\lambda_{1}$ ) of the major and minor MTs.

The decomposition in Eqs. (13) and (14) has one unique solution, but the assumption of fixed directions of the principal stress axes for the subsources is physically too restrictive. Therefore, we propose to weaken this assumption by systematic search among subsources with slightly deviated directions of the principal stress axes. To this, we apply a grid search for strike, dip and rake angles of the two DC sources with prescribed main axis difference being less than $20^{\circ}$. The optimal scalar seismic moments of each of the two tested DC sources $k$ and $l$ are obtained by linear inversion

$$
\tilde{\boldsymbol{b}}_{k l}=\left(\mathbf{B}_{k l}^{\mathrm{T}} \mathbf{B}_{k l}\right)^{-1}\left(\mathbf{B}_{k l}^{\mathrm{T}} \boldsymbol{n}\right)
$$




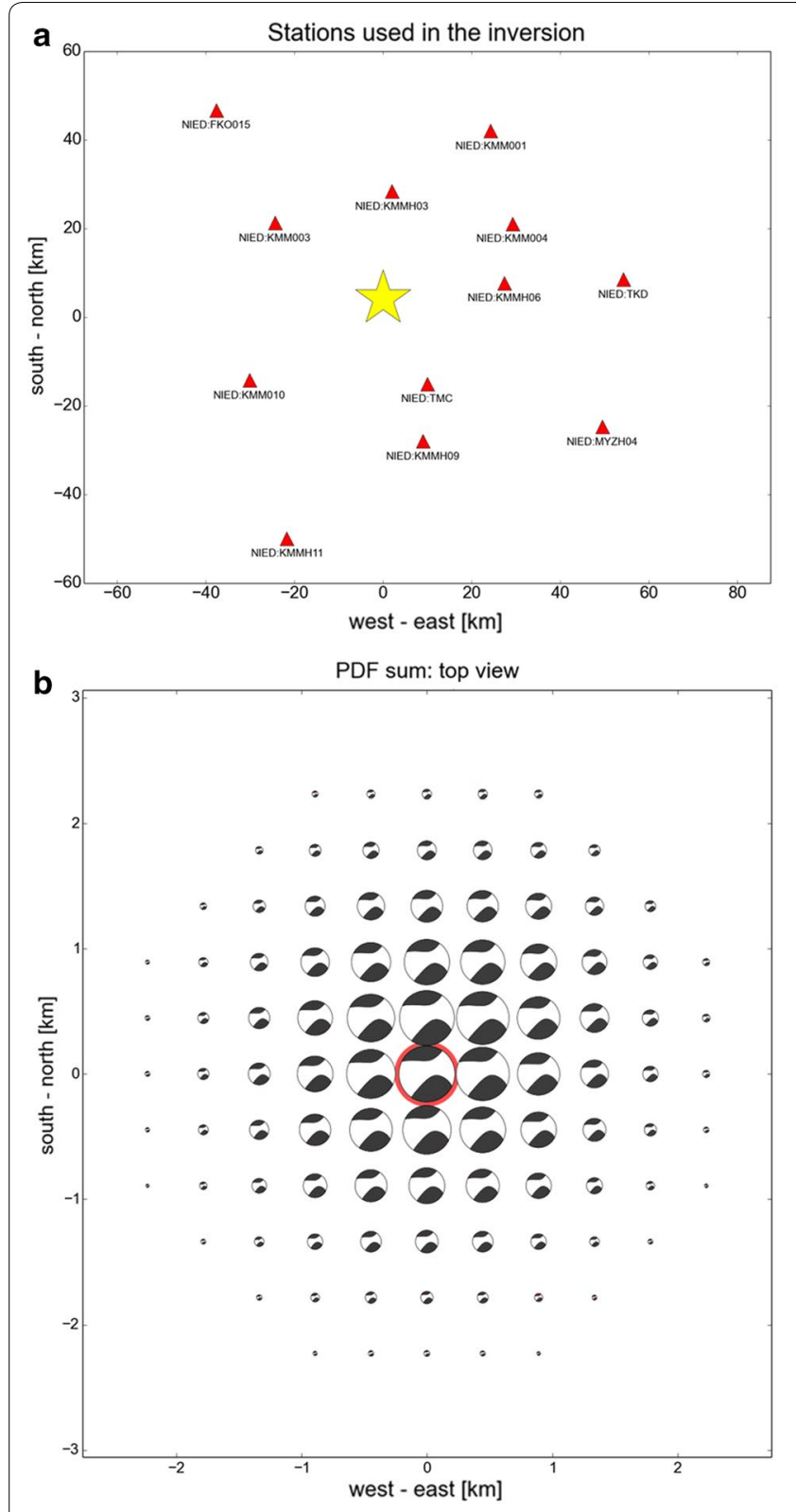

C inverted data - modeled (synt)

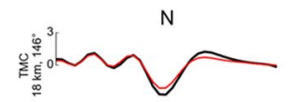<smiles>CC=CCOC1CC1</smiles>
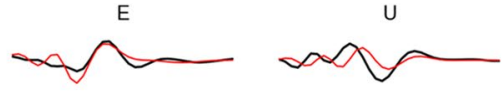<smiles>CCCC=CCCC</smiles>
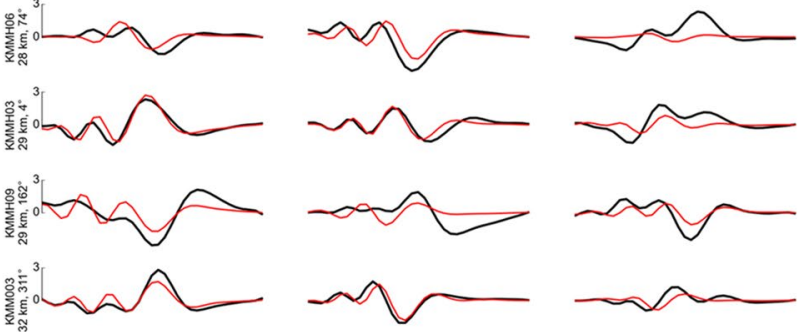

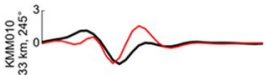
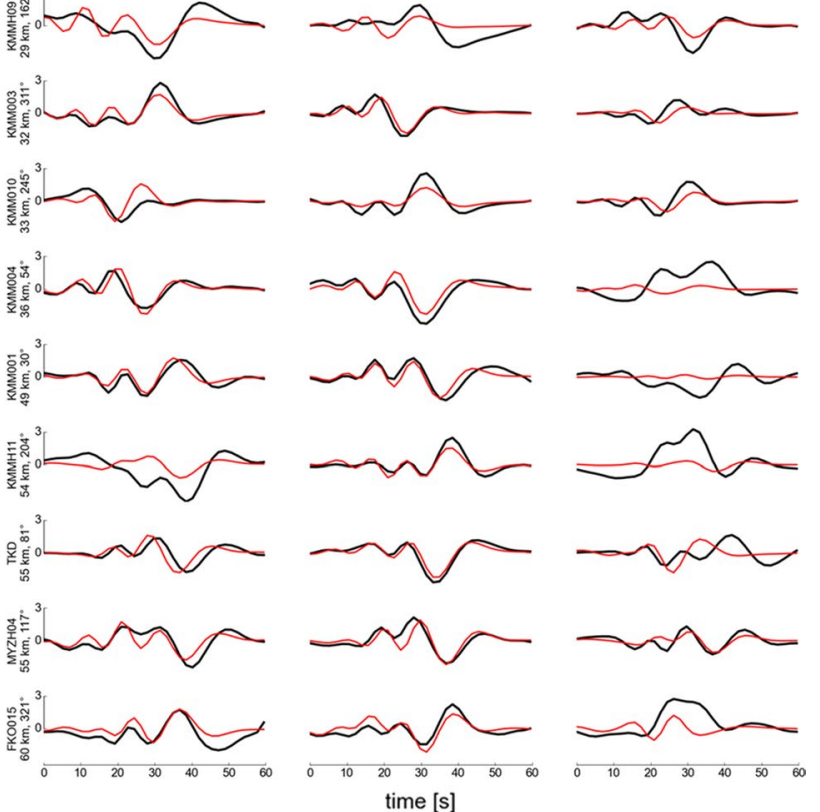

d

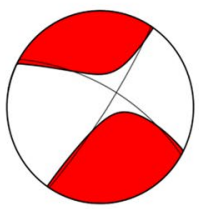

e

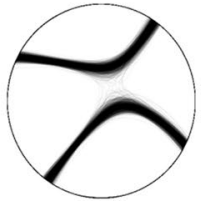

f

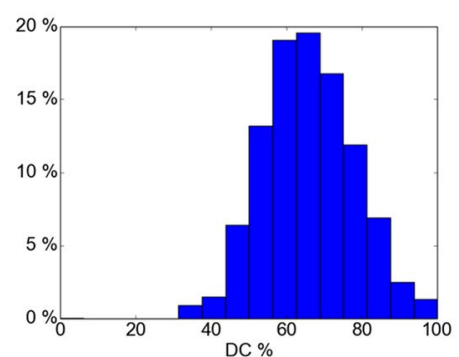

Fig. 3 CMT inversion for the M MMA 6.5 foreshock from 2016/4/14 21:26:35 JST (event No. 1). The figures are produced by modified program ISOLAObsPy of Vackár et al. 2017; a the map of strong motion stations (red triangles) used for the CMT inference; b marginal PDF of the CMT location in a horizontal slice indicated by the size of the beach-balls; the beach-balls depict inferred MTs at the individual spatial points. The beach-ball highlighted by red circle is the solution with the highest variance reduction (the best fitting solution); $\mathbf{c}$ the comparison between measured and synthetic standardized waveforms for the best fitting solution; $\mathbf{d}$ the beach-ball representation of the best fitting CMT; e the uncertainty of the mechanism depicted by 1000 random possible solutions drawn from the ten-dimensional posterior PDF; $\mathbf{f}$ histogram of the DC component

where $\boldsymbol{n}$ is vectorized non-DC MT $(9 \times 1$ column vector), $\mathbf{B}_{k l}$ is $9 \times 2$ matrix composed of two tested vectorized DC MTs with unit scalar seismic moments and $\tilde{\boldsymbol{b}}_{k l}$ is vector of the optimal scalar seismic moments. The fit of the summed DC MTs with the target non-DC MT $\boldsymbol{n}$ is measured by misfit (normalized variance)

$$
\ell_{k l}=\frac{\left\|\boldsymbol{n}-\mathbf{B}_{k l} \tilde{\boldsymbol{b}}_{k l}\right\|^{2}}{\|\boldsymbol{n}\|^{2}} \cdot 100 \%
$$

Note that the scalar seismic moments obtained by Eq. (15) may also have negative values; such solutions are considered unphysical and are thus excluded. Then, we 


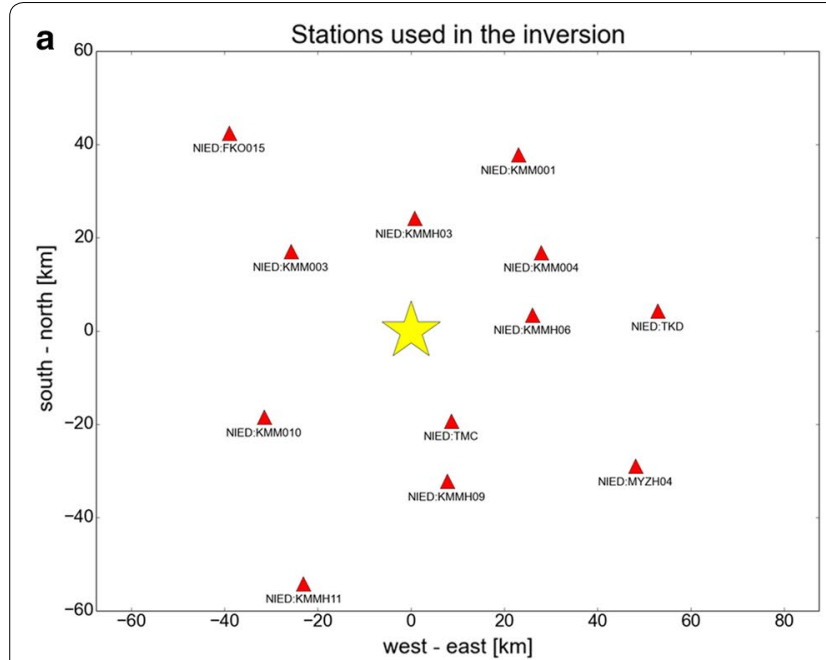

C inverted data - modeled (synt)
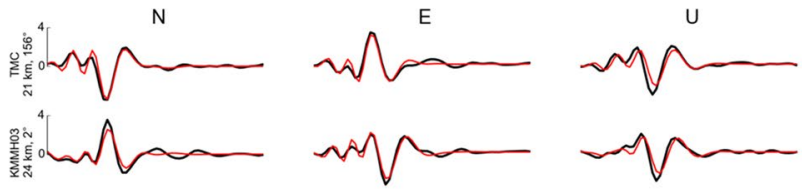

的
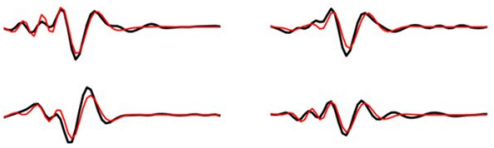

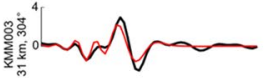
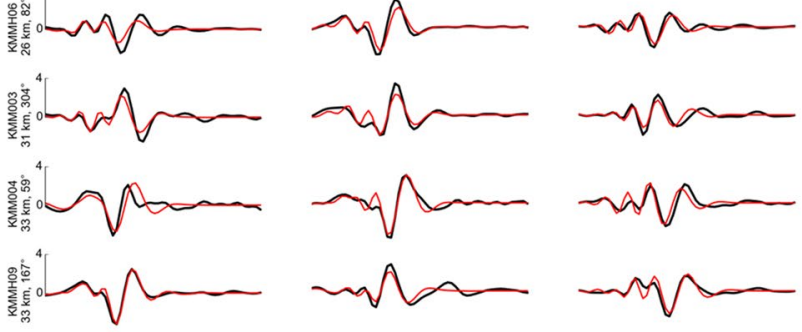

产
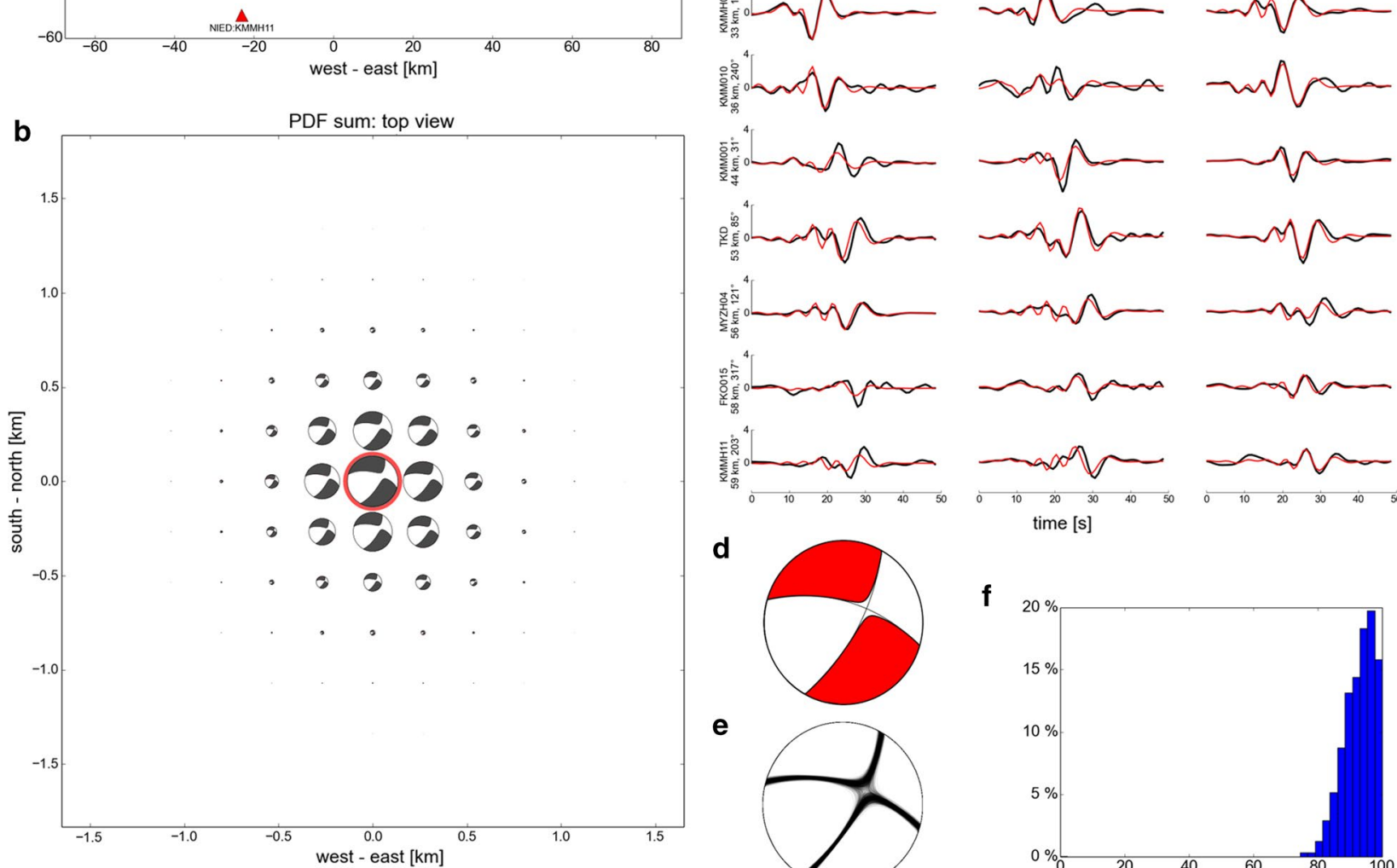

d

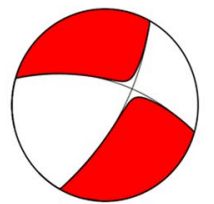

e
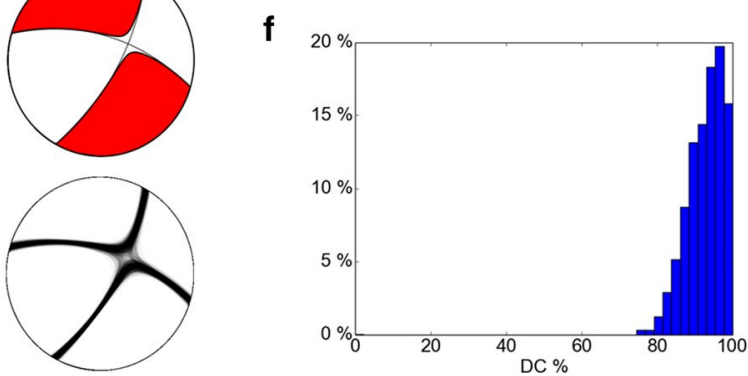

Fig. 4 Same as Fig. 3, but for the M MMA 5.8 foreshock from 2016/4/14 22:07:35 JST (event No. 4); a the map of strong motion stations (red triangles) used for the CMT inference; $\mathbf{b}$ marginal PDF of the CMT location in a horizontal slice indicated by the size of the beach-balls; the beach-balls depict inferred MTs at the individual spatial points. The beach-ball highlighted by red circle is the solution with the highest variance reduction (the best fitting solution); c the comparison between measured and synthetic standardized waveforms for the best fitting solution; $\mathbf{d}$ the beach-ball representation of the best fitting CMT; e the uncertainty of the mechanism depicted by 1000 random possible solutions drawn from the ten-dimensional posterior PDF; $\mathbf{f}$ histogram of the DC component

accept solutions with misfit (Eq. (16)) lower than $1 \%$. The result of this approach is a set of possible decompositions of non-DC MT into two DC MTs with prescribed main axis difference being less than $20^{\circ}$.

\section{Application of the non-DC MT decomposition}

The decomposition methodologies (Eqs. 13-16) are based on preserving main principal stress axis with the largest absolute eigenvalue $\left|\lambda_{1}\right|$; it may be either $P$-axis or $T$-axis of MTs. In the Kumamoto area, the stress field has $\sigma_{3}$ as the main principal stress in the NNW-SSE direction, while $\sigma_{1}$ and $\sigma_{2}$ in WSW-ENE and vertical directions, respectively, have similar size (Matsumoto et al. 2015, Fig. 7e). Hence, the decomposition of the selected non-DC MTs was performed to preserve $T$-axis (related to the stable $\sigma_{3}$ direction). 


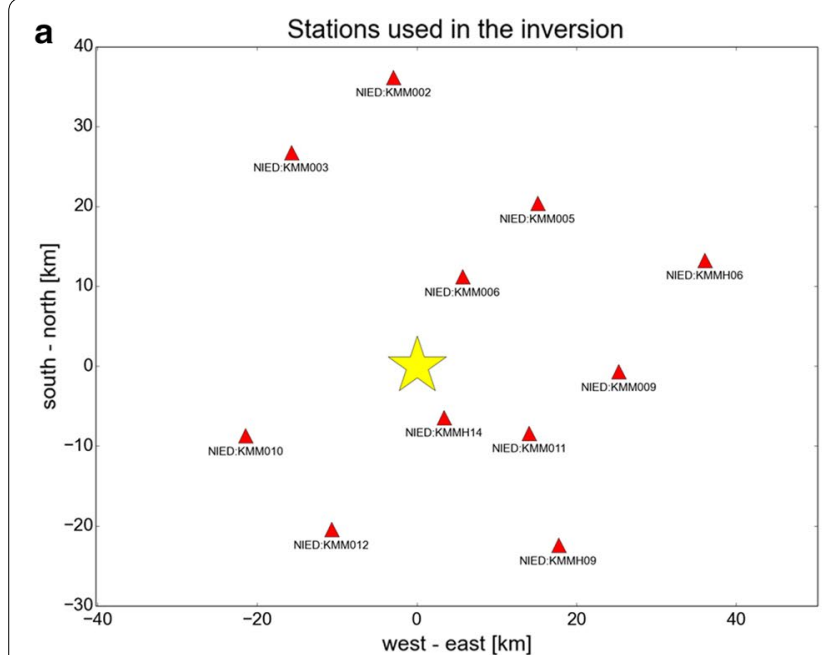

C
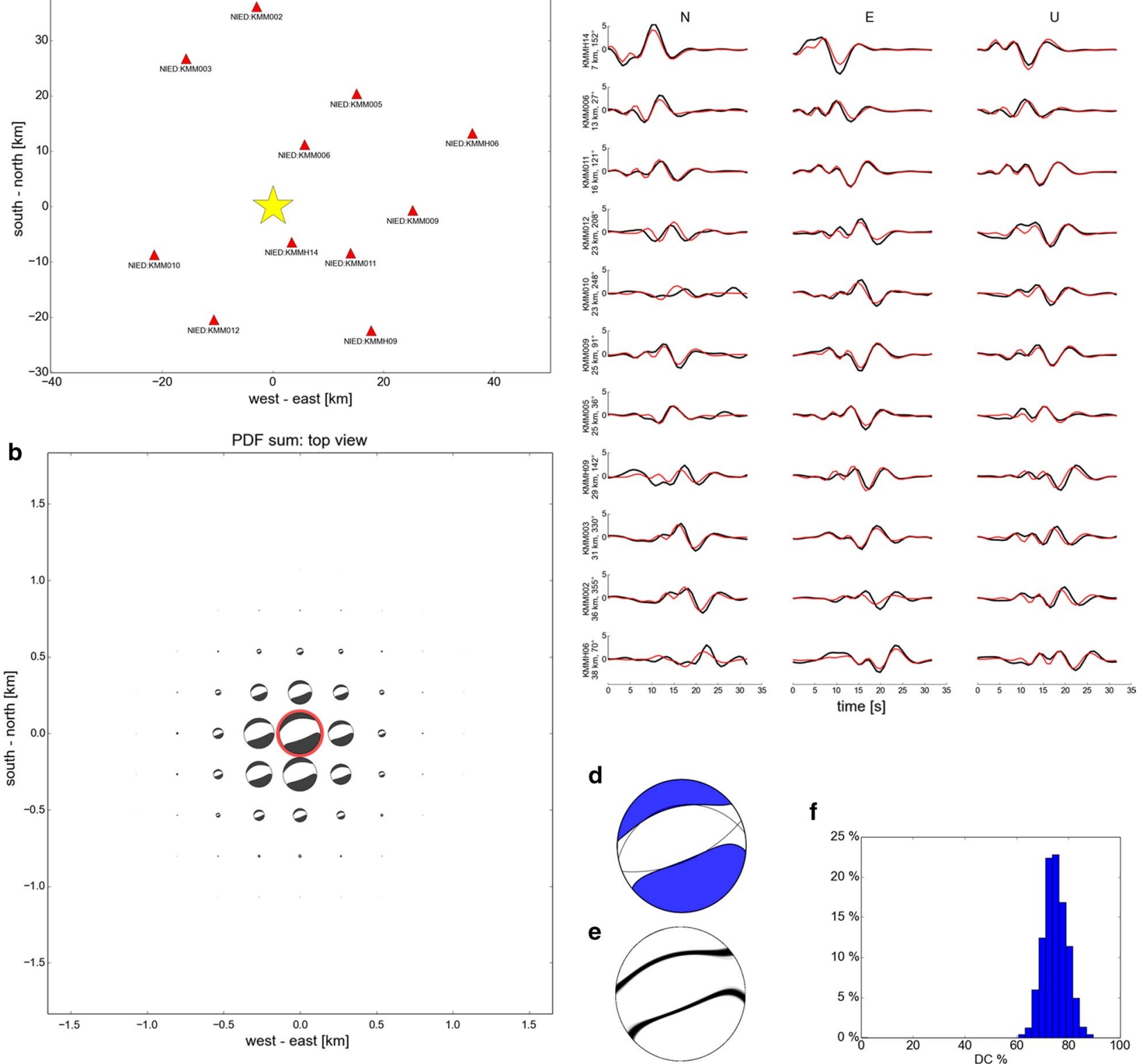

Fig. 5 Same as Fig. 3, but for the $M_{J M A} 5.4$ aftershock from 2016/4/16 16:02:01 JST (event No. 7); a the map of strong motion stations (red triangles) used for the CMT inference; $\mathbf{b}$ marginal PDF of the CMT location in a horizontal slice indicated by the size of the beach-balls; the beach-balls depict inferred MTs at the individual spatial points. The beach-ball highlighted by red circle is the solution with the highest variance reduction (the best fitting solution); c the comparison between measured and synthetic standardized waveforms for the best fitting solution; $\mathbf{d}$ the beach-ball representation of the best fitting CMT; e the uncertainty of the mechanism depicted by 1000 random possible solutions drawn from the ten-dimensional posterior PDF; $\mathbf{f}$ histogram of the DC component

Three of the inferred MTs of the Kumamoto earthquakes (events No. 1, 3 and 7) have significant CLVD component. Two of them (events No. 1 and 7) have $T$-axis as the main principal stress axis; hence, we analyzed those two in detail. The first analyzed earthquake is the strongest $M_{\mathrm{JMA}} 6.5$ strike-slip foreshock, and the second event is $M_{\mathrm{JMA}} 5.4$ normal faulting aftershock.
The decomposition of these non-DC MTs into major and minor DC sources is depicted in Fig. 7a, b. The summed MTs in Fig. 7 are in perfect agreement with our original non-DC MTs in Fig. 6. In the decomposition with preserved $T$-axis (Fig. 7a, b, and Appendix 2), the major MT is the best DC approximation of the shear seismic source, while minor MT represents 
Table 2 Parameters of the inferred CMT solutions together with their uncertainty in terms of double standard deviation of Gaussian function $(2 \sigma)$ fitted to the respective marginal PDF

\begin{tabular}{|c|c|c|c|c|c|c|c|c|c|}
\hline \multirow[t]{2}{*}{ No. } & \multicolumn{5}{|c|}{ CMT location } & \multicolumn{2}{|c|}{ DC component } & \multicolumn{2}{|c|}{$\begin{array}{l}\text { DC component } \\
\text { uncertainty }\end{array}$} \\
\hline & Lat. & Lon. & Depth (km) & $M_{w}$ & VR (\%) & $S / D / R\left(^{\circ}\right)$ & DC (\%) & $S / D / R\left(^{\circ}\right)$ & DC (\%) \\
\hline 1 & 32.780 & 130.809 & 8.1 & 6.1 & 44 & $33 / 82 /-155$ & 64 & $3 / 7 / 9$ & \pm 24 \\
\hline 2 & 32.696 & 130.768 & 3.8 & 6.0 & 58 & $212 / 77 / 178$ & 87 & $2 / 9 / 12$ & \pm 20 \\
\hline 3 & 32.862 & 130.856 & 8.4 & 5.7 & 59 & $294 / 37 /-48$ & 67 & $6 / 4 / 8$ & \pm 16 \\
\hline 4 & 32.780 & 130.823 & 8.3 & 5.4 & 73 & 29/69/-149 & 94 & $2 / 3 / 4$ & \pm 10 \\
\hline 5 & 32.765 & 130.760 & 13.0 & 5.0 & 45 & $6 / 72 /-142$ & 79 & $5 / 7 / 10$ & \pm 14 \\
\hline 6 & 32.860 & 130.835 & 10.0 & 5.2 & 60 & $83 / 62 /-71$ & 89 & $3 / 2 / 3$ & \pm 10 \\
\hline 7 & 32.692 & 130.716 & 7.8 & 5.2 & 74 & $68 / 63 /-95$ & 75 & $3 / 2 / 3$ & \pm 8 \\
\hline 8 & 32.765 & 130.803 & 9.9 & 4.9 & 54 & 16/76/-163 & 92 & $2 / 4 / 4$ & \pm 14 \\
\hline 9 & 32.679 & 130.735 & 8.1 & 4.9 & 71 & $211 / 66 / 175$ & 90 & $2 / 3 / 3$ & \pm 8 \\
\hline 10 & 32.745 & 130.752 & 5.7 & 4.7 & 53 & $215 / 81 /-165$ & 83 & $2 / 7 / 8$ & \pm 22 \\
\hline 11 & 32.800 & 130.788 & 5.7 & 4.6 & 61 & $79 / 29 /-104$ & 98 & $8 / 2 / 8$ & \pm 12 \\
\hline
\end{tabular}

$V R$ variance reduction, $M_{w}$ moment magnitude, $S / D / R$ strike/dip/rake

complexity of the faulting (secondary faulting mechanism). It has to be emphasized that the major and minor DC sources cannot be understood as two asperities of an activated fault system; the decomposition is merely mathematical description of a complex earthquake source.

Better understanding can be gained from the examples of possible decomposition provided by the grid search approach (Fig. 7c, d), documenting the non-uniqueness of the decomposition. Nevertheless, all the selected examples are, generally, a combination of a strike-slip and a normal dip-slip mechanism (as shown in Fig. 7), which is consistent with the tectonic settings of the intersection of the Hinagu and Futagawa fault zones.

\section{Geometry of the activated ruptures}

The inferred CMTs of the analyzed events exhibit significant systematic spatial variations throughout the source region (Fig. 8). Analyzed CMTs of foreshocks are strikeslip events located near the surface traces of the Hinagu and Futagawa faults (red DC beach-balls in Fig. 8). Contrarily, aftershocks have various mechanisms with majority of normal dip-slips (blue DC beach-balls in Fig. 8). We estimate that more than $99 \%$ of the total scalar seismic moment of the Kumamoto sequence in studied area was released by the analyzed events together with the $M_{\text {IMA }} 7.3$ mainshock. Hence, we aim to construct the network of major faults and ruptures, which were activated within the analyzed sequence, from the CMT solutions.

Firstly, we determine the preferred fault planes out of the two MT nodal planes based on the (a) orientation of surface traces of the faults; (b) geometry of clusters of the relocated hypocenters; and (c) by the mutual co-location of the hypocenter and centroid (so-called $\mathrm{H}-\mathrm{C}$ method, Zahradník et al. 2008). In the latter method, the fault plane is identified as that one from two nodal planes of CMT that encompasses the hypocenter location in 3D. The assumption is that ruptures propagate from the hypocenter along a fault plane described by the CMT solution. Major surface traces of the Hinagu and Futagawa faults are oriented in the NE-SW direction, which is indicative for the strike-slip fault planes. The strike-slip fault planes of Hinagu fault zone are noticeable also in the vertical cross sections in Fig. 9 showing hypocenters of the Kumamoto earthquakes as inferred by Kato et al. (2016). The $\mathrm{H}-\mathrm{C}$ method is useful, especially for the normal dip-slip aftershocks with unclear evidence of surface traces of faults; moreover, it supports also assumed orientation of strike-slip fault planes. Hence, the strike-slip fault planes are identified with higher certainty than the dip-slip fault planes. Determined preferable nodal planes of the sources are listed in Table 2 by means of their strike, dip and rake angles.

Secondly, we estimate the rupture area of the analyzed earthquakes from their scalar seismic moments. The adopted empirical relationship from Somerville et al. (1999) is based on the self-similar scaling of the large to midsize crustal earthquakes. The rupture area $A$ in square kilometers is given by

$$
A=2.23 \cdot 10^{-15} \cdot M_{0}^{2 / 3}
$$

where the scalar seismic moment $M_{0}$ is in dyne-cm. The estimated rupture areas supplemented by rupture lengths $L$, assuming square geometry of the fault planes, are listed in Table 3. The rupture area and geometry of the 


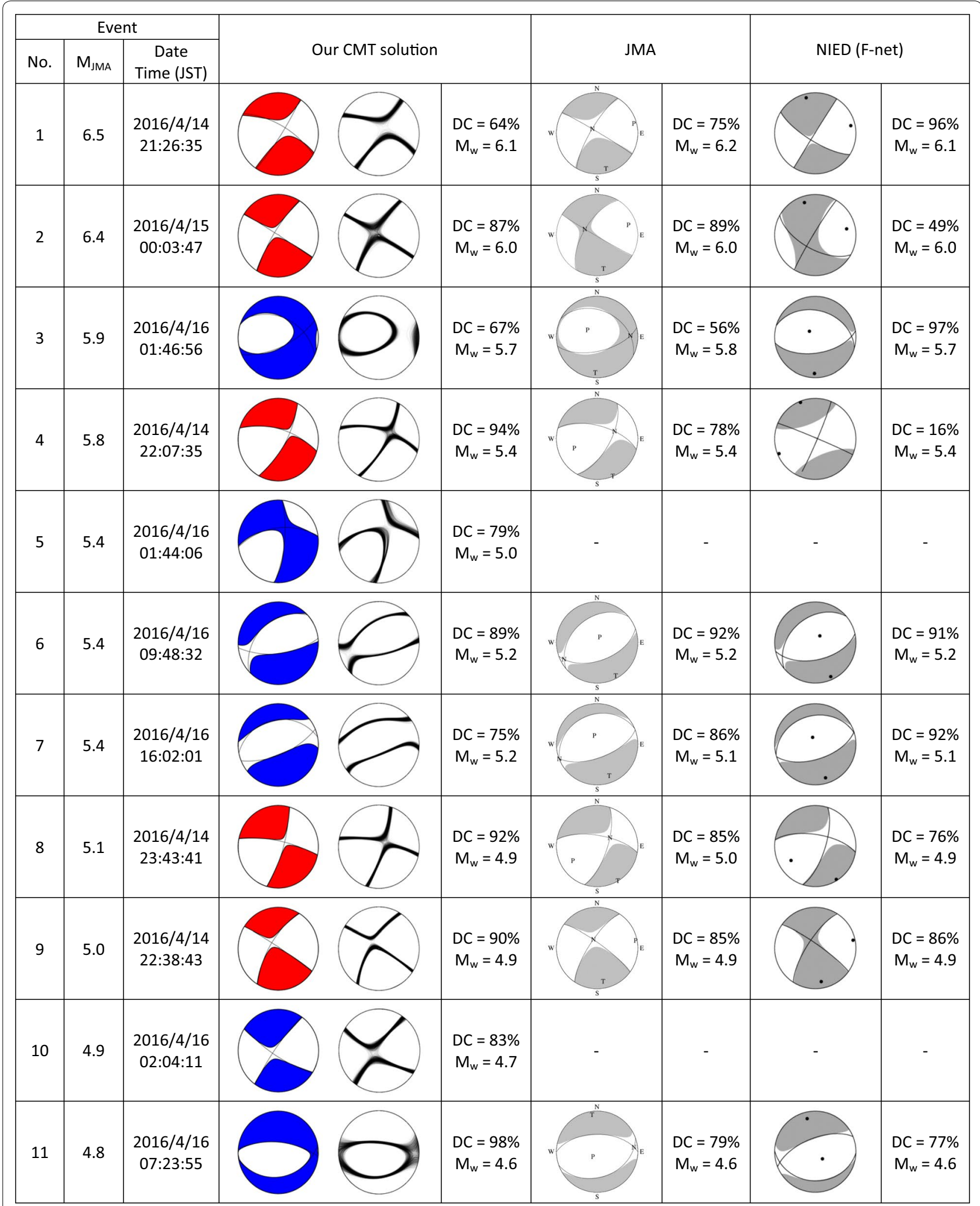

Fig. 6 Beach-ball representation of the best fitting MTs for all the inferred events. Our MT solutions are supplemented by uncertainty of the mechanism depicted by 1000 random possible solutions drawn from the ten-dimensional posterior PDF. JMA and NIED solutions are adopted directly from the routine MT catalogues of these agencies accessed through Web 


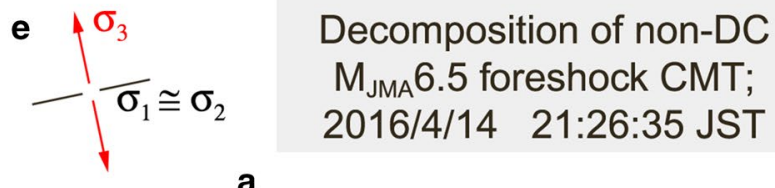

a
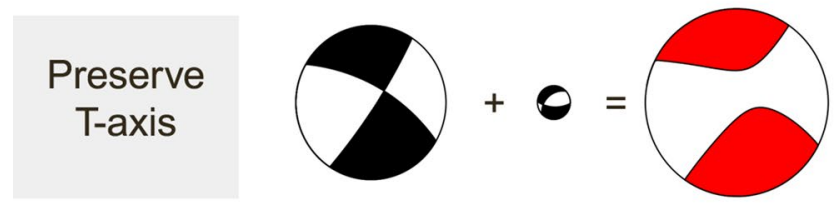

C
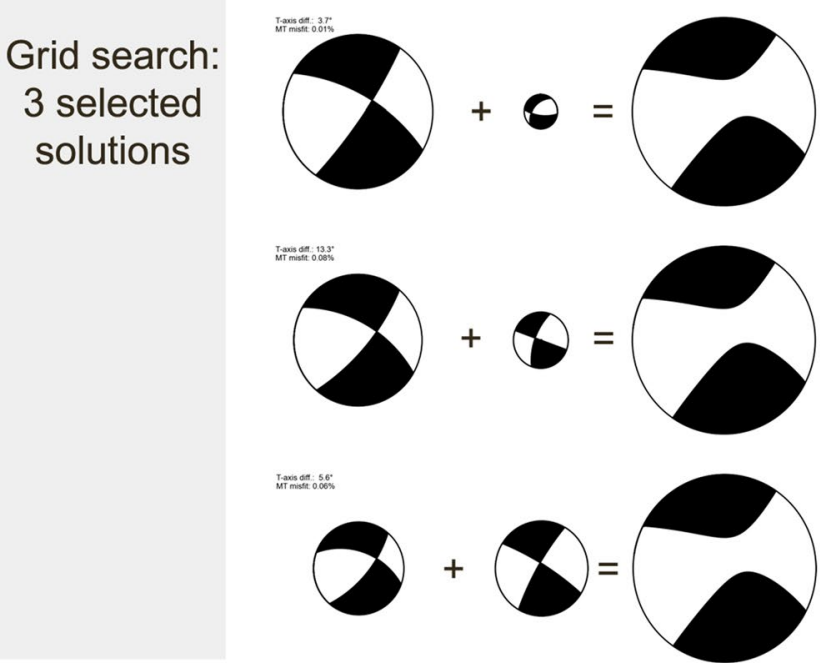

Decomposition of non-DC $\mathrm{M}_{\text {JMA }} 5.4$ aftershock CMT; 2016/4/16 16:02:01 JST

b

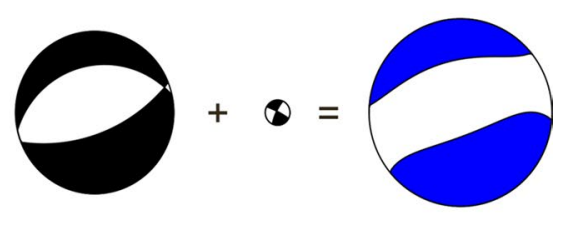

d
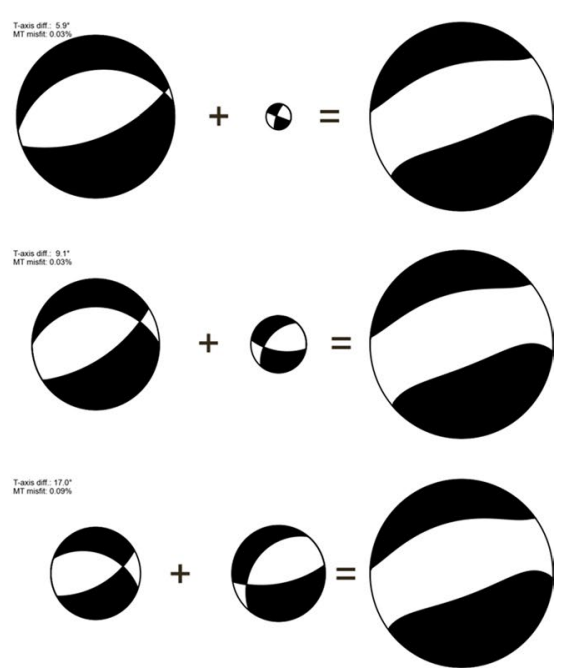

Fig. 7 Decomposition of non-DC MTs of the $M_{\mathrm{JMA}} 6.5$ foreshock (left column) and the $M_{\mathrm{JMA}} 5.4$ aftershock (right column) into combination of two DC MTs; DC MTs are shown together with their sum $\mathbf{M T}_{1}+\mathbf{M T}_{2}=\mathbf{M T}_{\text {sum }}$ by trinity of beach-balls; radius of beach-balls is proportional to scalar seismic moment; $\mathbf{a}, \mathbf{b}$ are unique solutions of the MT decomposition preserving main (T-)axis (Eqs. (13) and (14)); $\mathbf{c}$, d are selected representative solutions of the non-unique MT decomposition by the grid search approach, where the scalar moments were obtained by a linear inversion (Eq. (15)); $\mathbf{e}$ the regional stress field indicated by directions of $\sigma_{1}, \sigma_{2}$ and $\sigma_{3}$. Adopted from Matsumoto et al. (2015)

$M_{\mathrm{JMA}} 7.3$ mainshock are adopted from the slip inversion by Asano and Iwata (2016), having area of $756 \mathrm{~km}^{2}$.

We have centered the assumed rupture planes defined by their spatial orientation (Table 2) and rupture size (Table 3) in their respective CMT locations (Table 2) and plotted them in 3D visualization program ParaView (Fig. 10). As locations of the inferred CMTs and also hypocenters are subjects of uncertainty (estimated to be up to $1.5 \mathrm{~km}$ for CMTs), the assumed fault planes do not necessarily cross perfectly the hypocenter. The minimum distance of the hypocenters from the respective fault planes is shown in Table 3 as parameter $R$. Foreshocks' major ruptures (red squares in Fig. 10) continuously cover the northernmost part of the Hinagu fault zone, having length of approximately $20 \mathrm{~km}$. They span from the surface to the depth of approximately $14 \mathrm{~km}$. The aftershocks' major ruptures (blue squares in Fig. 10) spread NW along the adopted fault plane of the $M_{\mathrm{IMA}} 7.3$ mainshock (yellow rectangles in Fig. 10). Moreover, three of the inferred aftershock's ruptures (events No. 3, 5 and 7) intersect the mainshock fault plane.

\section{Discussion}

\section{Solutions in seismotectonic framework}

The relationship between the earthquakes, active tectonics and faults may play role in the local seismic hazard assessment. The constructed network of activated ruptures (Fig. 10) represents such seismotectonic description of the intersection of the Hinagu and Futagawa fault zones. Foreshocks (red beach-balls in Fig. 8) imply rightlateral strike-slip movements in the NE-SW direction in the Hinagu fault zone. Those ruptures located close to the intersection of the Hinagu and Futagawa fault zones are dipping slightly to ESE, while those in the southern area are dipping to WNW. The activated ruptures span from surface to depth of approximately $14 \mathrm{~km}$. Contrarily, aftershocks are mostly normal dip-slip events (blue beach-balls in Fig. 8) and spread NW along the assumed 


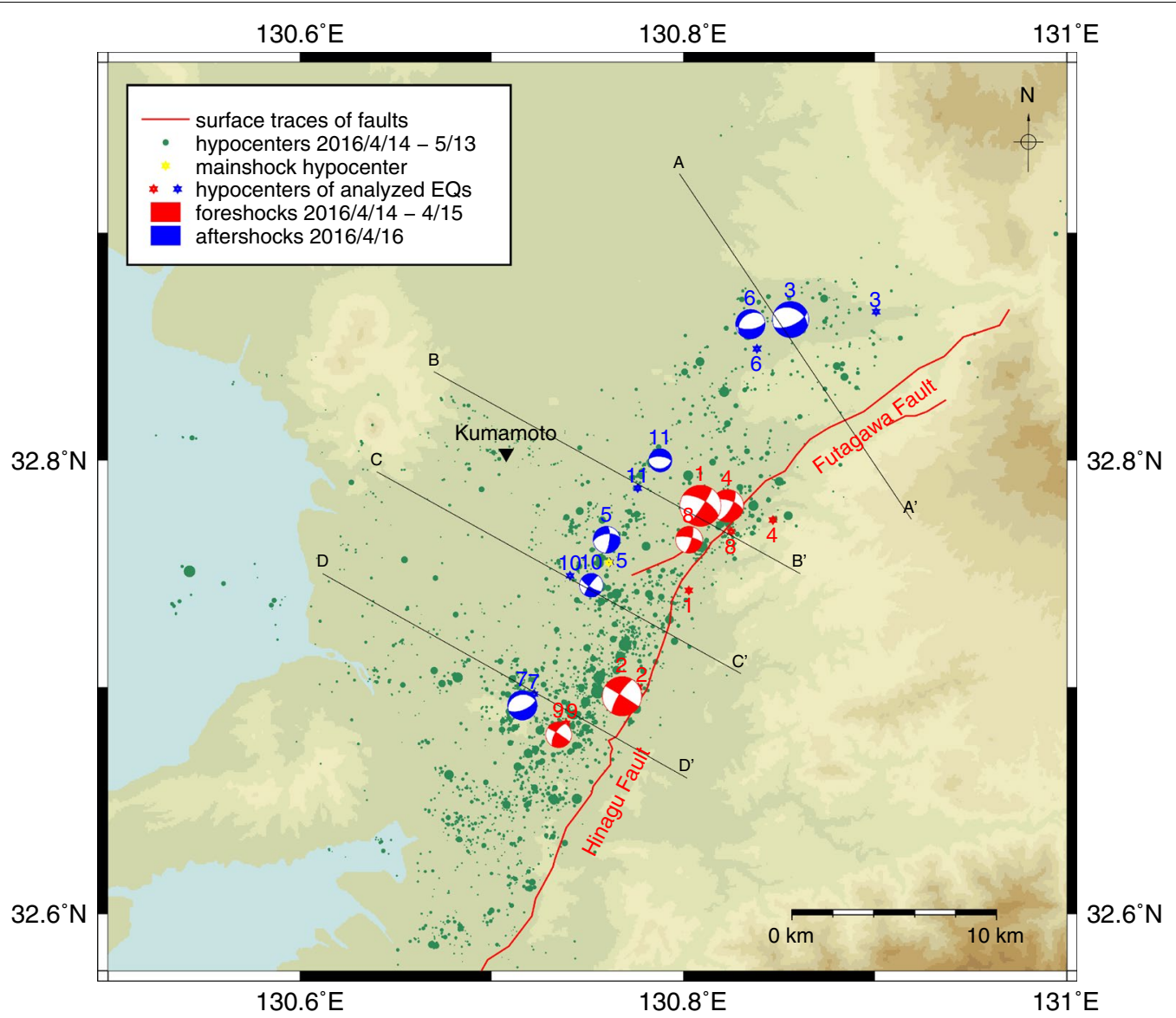

Fig. 8 Map of inferred CMTs of the Kumamoto earthquake sequence; CMTs are shown by beach-ball representation of the best DC source. The background seismicity is adopted from Kato et al. (2016). The sizes of the circles are proportional to the JMA magnitude of the events. Events are numbered according to Table 2. Black lines are traces of vertical cross sections shown in Fig. 9. For details, see legend

fault plane of the $M_{\mathrm{IMA}} 7.3$ mainshock (see Fig. 10), where the surface subsidence occurred as documented by InSAR (Himematsu and Furuya 2016). Aftershock's ruptures are situated at depths greater than $5 \mathrm{~km}$, close to the assumed fault plane of the mainshock (adopted from Asano and Iwata 2016), and three of them intersect the mainshock fault plane. These findings imply that foreshocks and partially also mainshock are driven by stresses of the NE-SW shear zone (western extension of the MTL), while aftershocks are mostly related to the N-S extensional stress regime of Beppu-Shimabara graben (Kamata and Kodama 1994), being triggered by the mainshock. This is confirmed by principal stress axes analysis performed by code of Vavrycuk (2014), see Fig. 11, showing that the $\mathrm{N}-\mathrm{S}$ extensional stress $\sigma_{3}$ is stable (blue dots in Fig. 11a, b), while main principal stress $\sigma_{1}$ is oriented NE-SW and vertically for foreshocks and aftershocks, respectively (red dots in Fig. 11a, b).

Co-activation of the right-lateral strike-slips with normal faulting ruptures through the sequence was introduced also by static slip model from geodetic data
(Himematsu and Furuya 2016; Kobayashi 2017). Field investigation by Toda et al. (2016) shows that surface displacements along the previously mapped active fault traces of the Hinagu-Futagawa fault zone are dominated by right-lateral strike-slip surface displacement up to $2 \mathrm{~m}$. A normal surface rupture zone of about $10 \mathrm{~km}$ in length dipping to northwest, which is parallel to the Futagawa fault outside the Aso caldera, was also reported by Toda et al. (2016), and its maximum co-seismic displacement is also up to $2 \mathrm{~m}$. The normal dip-slip aftershocks that occurred along the NW edge of the mainshock rupture had no clear relationship with co-seismic surface ruptures; however, minor surface ruptures in downtown of Kumamoto City have been mapped by InSAR (Himematsu and Furuya 2016) and field survey (Goto et al. 2017). The field investigations imply the complex surface phenomena and tectonic settings in this region. Further surveys on imaging causative source faults beneath the surface are necessary to investigate the relationship between the surface ruptures and the geometry of earthquake source faults. 


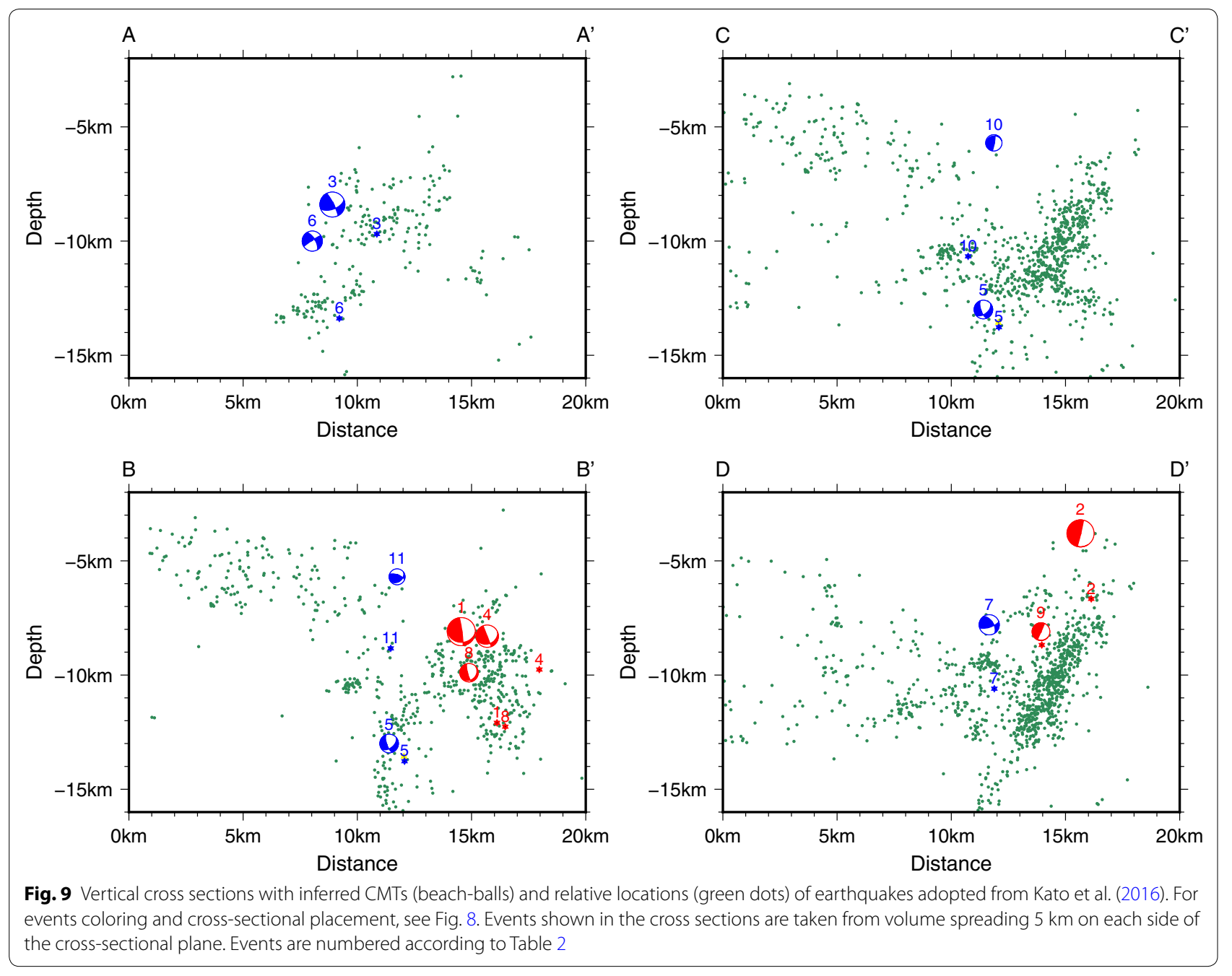

Finally, here we summarize the temporal seismotectonic evolution of the Kumamoto sequence:

- Activity started on April 14th by the $M_{\mathrm{JMA}} 6.5$ foreshock close to the intersection of the Hinagu and Futagawa fault zones as right-lateral strike-slip shear movement in the NE-SW direction on fault plane(s) dipping slightly to the ESE (events No. 1 and 4).

- Right-lateral strike-slip shear movements continued by simultaneous activity in the northern (dipping to the ESE) and southern (dipping to the WNW) segments of the Hinagu fault zone (events No. 8 and 9).

- On April 15th, activity migrated to the southern (dipping to the WNW) segment of the Hinagu fault zone. The activity comprised the second largest foreshock $M_{\text {TMA }} 6.4$ (event No. 2).

- This was followed by the mainshock on April 16th as right-lateral shear slips complemented by normal dip-slip in the Futagawa fault segment in the later phase of the rupture propagation.
- Aftershocks in the area of interest were mostly normal dip-slip events, spreading along the NW edge of the mainshock rupture (events No. 3, 6, 7 and 11).

\section{Complexity of activated ruptures}

The local stress field conditions (e.g., Matsumoto et al. 2015) and seismotectonic settings of the intersection of the Hinagu and Futagawa fault zones imply combination of a strike-slip and a normal dip-slip shearing mechanism. Indeed, the source models for the mainshock (e.g., Asano and Iwata 2016; Kubo et al. 2016) suggest simultaneous right-lateral strike-slip shear movement complemented by normal dip-slip movement of the Futagawa fault segment. The rupture of the mainshock then has to be complex and segmented to two or more fault planes (as suggested by the mainshock source models).

The analyzed foreshocks and aftershocks are mostly right-lateral strike-slip and a normal dip-slip shearing event with insignificant CLVD component and hence may be assumed as single fault plane ruptures. The 
Table 3 Rupture area of the analyzed Kumamoto earthquakes estimated from empirical relation by Somerville et al. (1999) in Eq. (17)

\begin{tabular}{llccc}
\hline Event & & $\boldsymbol{A}\left(\mathbf{k m}^{\mathbf{2}}\right)$ & $\boldsymbol{L}(\mathbf{k m})$ & $\boldsymbol{R}(\mathbf{k m})$ \\
\hline No. & $\boldsymbol{M}_{\mathbf{J M A}}$ & & & \\
\hline 1 & 6.5 & 155.4 & 12.5 & 1.3 \\
2 & 6.4 & 110.3 & 10.5 & 1.1 \\
3 & 5.9 & 62.5 & 7.9 & 0.2 \\
4 & 5.8 & 28.8 & 5.4 & 1.6 \\
5 & 5.4 & 10.3 & 3.2 & 0.0 \\
6 & 5.4 & 16.1 & 4.0 & 1.7 \\
7 & 5.4 & 16.2 & 4.0 & 1.6 \\
8 & 5.1 & 9.8 & 3.1 & 1.7 \\
9 & 5.0 & 8.2 & 2.9 & 0.3 \\
10 & 4.9 & 5.3 & 2.3 & 3.9 \\
11 & 4.8 & 4.9 & 2.2 & 2.6 \\
\hline
\end{tabular}

$A$ is total rupture area and $L$ is rupture length assuming square geometry of the fault plane. Parameter $R$ is the minimum distance in $3 D$ between the hypocenter and the respective fault plane

exceptions are the $M_{\mathrm{IMA}} 6.5$ foreshock (event No. 1) and the $M_{\mathrm{IMA}} 5.4$ aftershock (event No. 7) with significant CLVD component and $T$-axis as the main principal stress axis. These two events can be interpreted as a result of complex ruptures composed of right-lateral strike-slip and a normal dip-slip fault plane with preserved $T$-axis (Fig. 7). The assumption of preserved $T$-axis is in accord the inferred principal stress in Fig. 11, where $\sigma_{3}$ is stable in $\mathrm{N}-\mathrm{S}$ direction. Such interpretation of non-DC component is supported by the static slip model for the $M_{\mathrm{IMA}} 6.5$ foreshock inferred from InSAR data (Kobayashi 2017), being composed of right-lateral strike-slip displacement on the Hinagu fault segment and normal dip-slip displacement on the Futagawa fault segment.

\section{Comparison with routine MT catalogues}

The MTs for most of the processed events were also inferred routinely by JMA and NIED institutions. Our and JMA approaches infer CMTs by searching the centroid location in both horizontal and vertical directions. Contrarily, NIED fixes the horizontal centroid location at the (revised) JMA epicenter and searches for the centroid depth only.

Our MTs are compared with solutions from JMA and NIED catalogues in Fig. 6. Our solutions generally agree with both agency MTs in terms of nodal planes angles, while non-DC components agree better with JMA (e.g., see the DC component percentage for the $M_{\mathrm{IMA}} 6.4$ foreshock, No. 2 in Fig. 6). This can be related to the use of higher number of records from shorter epicenter distances and searching CMT in both horizontal and vertical directions in our and JMA approaches. Moreover,

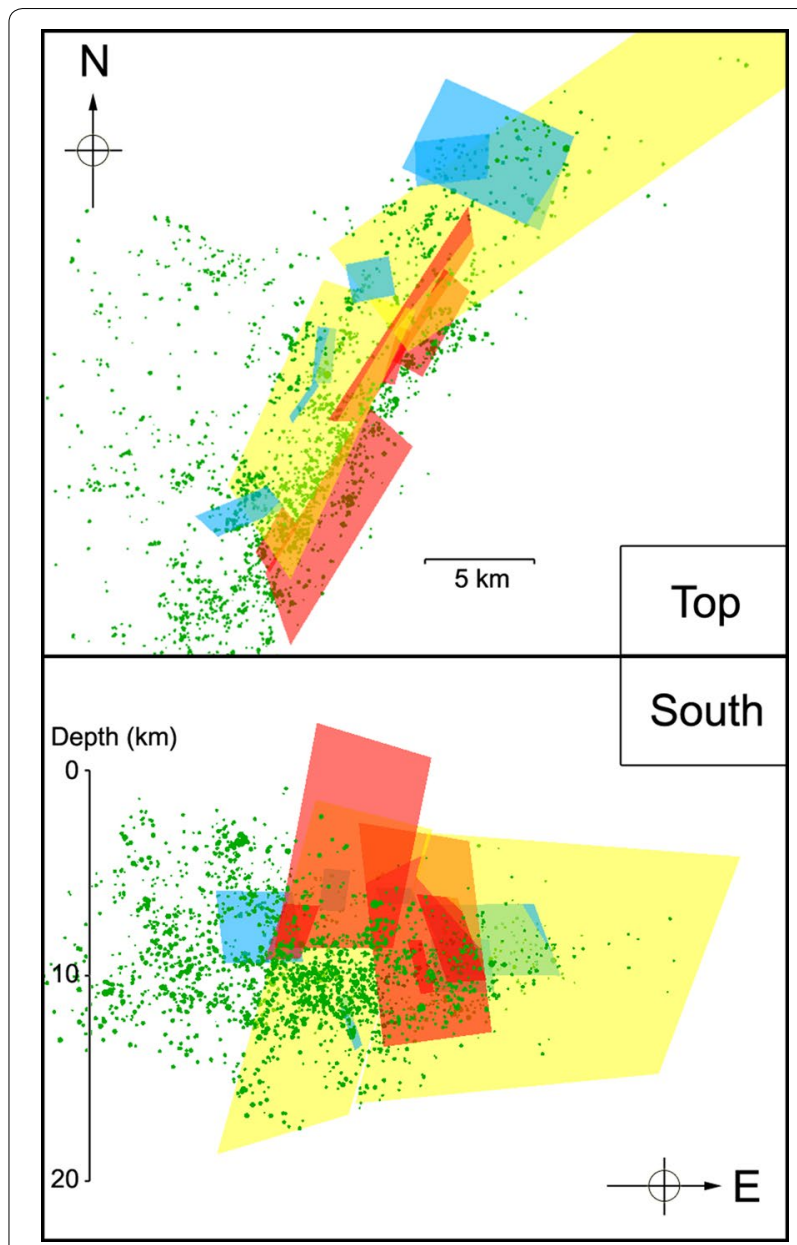

Fig. 10 Visualization of the assumed activated fault planes in top and south-side view; red squares = foreshocks' ruptures; blue squares $=$ aftershocks'ruptures; yellow rectangles $=$ mainshock's rupture adopted from Asano and Iwata (2016); green dots = relative locations of earthquakes inferred by Kato et al. (2016) for period April 14-May 13, 2016. The scale in figure is only orientative, because of used perspective projection

uncertainty estimate by our approach allows the assessment of reliability of the inferred non-DC component. For example, in cases of events No. 2 and 11 (Fig. 6), the JMA and our solutions exhibit opposite signs of the CLVD component, but this difference is within the estimated uncertainty.

\section{Conclusions}

We have presented application of the innovative Bayesian full-waveform CMT inversion method, which takes into account uncertainty of the velocity model. The approach allows us to reliably assess the uncertainty of the source parameters, which proved to be beneficial in terms of interpretation of the results (statistical significance of selected source parameters). Additionally, we 
a

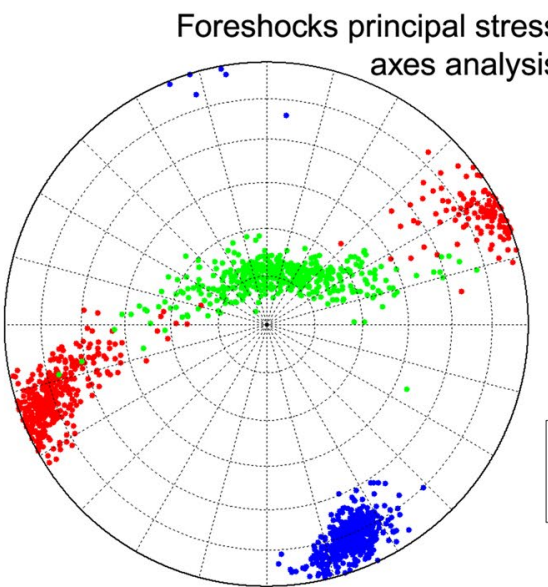

C

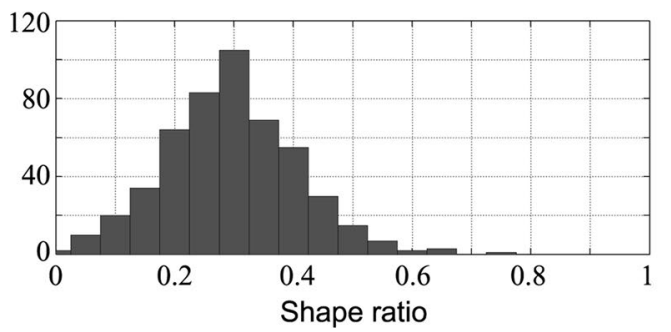

b
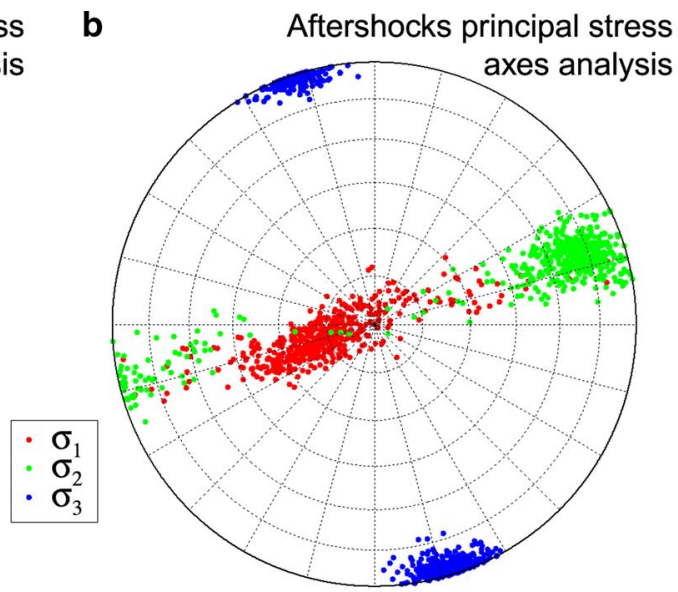

d

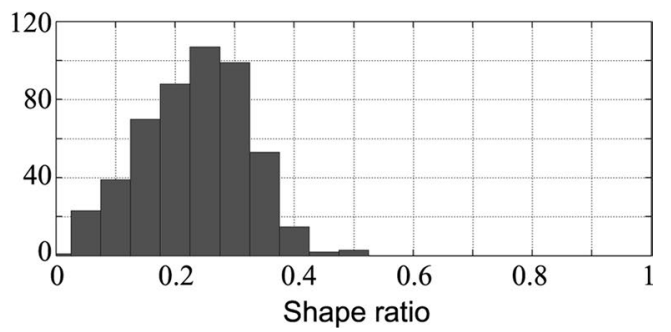

Fig. 11 Principal stress axes analysis for foreshocks (left) and aftershocks (right) by method of Michael (1984) with uncertainty estimate coded by Vavryčuk (2014); panels a, b show confidence limits of principal stress axes visualized by 500 randomly perturbed pure shear solutions by the approach of Vavryčuk (2014) for foreshocks and aftershocks, respectively. In panels $\mathbf{c}, \mathbf{d}$ are histograms of their respective shape ratios defined as $=\frac{\sigma_{1}-\sigma_{2}}{\sigma_{1}-\sigma_{3}}$. Note that the relatively low shape ratios imply $\sigma_{1} \approx \sigma_{2}$

have implemented decomposition of MT with significant CLVD component into two shear MTs with preserved $T$-axis as a physical constraint.

The methodology has been applied to significant earthquakes from the Kumamoto sequence of April 2016 with $M_{\text {JMA }}$ magnitude in range of 4.8-6.5. The quality of the inferred solutions is mostly high as we have used dense network of local to regional receivers. The inferred CMT solutions show systematic spatial and temporal variations. Hence, we have estimated geometry of the major activated ruptures and interpreted them in the seismotectonic framework. Foreshocks imply right-lateral NE-SW strike-slip movements in the Hinagu fault zone. Aftershocks are mostly normal dip-slip events spreading along the NW edge of the assumed mainshock fault plane. Moreover, the inferred CMTs with significant CLVD component may suggest a complex source process. These events can be interpreted as a result of complex ruptures composed of right-lateral strike-slip and a normal dip-slip fault plane. Our model of major activated ruptures inferred from seismic data is consistent with the local tectonic settings, stress field conditions and geodetic data.

\section{Authors' contributions}

MH analyzed the data and drafted the manuscript. KA suggested to analyze 2016 Kumamoto sequence and supported the research by knowledge of the local seismotectonic conditions. FG contributed mainly in methodology and with primary draft corrections. All authors read and approved the final manuscript.

\section{Author details}

${ }^{1}$ Faculty of Mathematics and Physics, Charles University, Prague, Czech Republic. ${ }^{2}$ Disaster Prevention Research Institute, Kyoto University, Gokasho, Uji, Kyoto, Japan.

\section{Acknowledgements}

The authors thank all operators involved in station maintenance at K-NET, KiKnet and F-net networks. We appreciate relative locations of hypocenters (same as in Kato et al. 2016) provided by A. Kato from Earthquake Research Institute, University of Tokyo, Japan. Generic Mapping Tools (Wessel and Smith 1998) was used to draw the figures. This paper is based on achievements of the collaborative research program (28S-02) of the Disaster Prevention Research Institute of Kyoto University. We acknowledge financial support by the Grant Agency of the Charles University project GAUK-728916 and Charles University Grant SW 260447/2017. We are grateful to two anonymous reviewers for their comments that improved the original manuscript.

\section{Competing interests}

The authors declare that they have no competing interests.

\section{Appendix 1: Inferred most likely MT solutions for Kumamoto earthquakes}

See Table 4. 
Table 4 MT elements of the inferred solutions for Kumamoto earthquakes in Harvard/USGS form

\begin{tabular}{|c|c|c|c|c|c|}
\hline \multicolumn{4}{|c|}{ Event } & \multirow{2}{*}{$\begin{array}{l}\text { Harvard/USGS MT } \\
{\left[M_{\mathrm{rr}} M_{\mathrm{tt}} M_{\mathrm{pp}} M_{\mathrm{rt}} M_{\mathrm{rp}} M_{\mathrm{tp}}\right](\mathrm{Nm})}\end{array}$} & \multirow[t]{2}{*}{$M_{0}(\mathrm{Nm})$} \\
\hline No. & $M_{\text {JMA }}$ & Date & Time (JST) & & \\
\hline 1 & 6.5 & $2016 / 4 / 14$ & $21: 26: 35$ & {$[-0.421 .56-1.14-0.33-0.530 .73]^{*} 1 e+18$} & $1.84 * 1 \mathrm{e}+18$ \\
\hline 2 & 6.4 & 2016/4/15 & 00:03:47 & {$[-0.499 .49-9.00-2.390 .844 .56] * 1 e+17$} & $1.10 * 1 e+18$ \\
\hline 3 & 5.9 & 2016/4/16 & 01:46:56 & {$[-3.263 .52-0.26-1.64-2.17-0.18] * 1 e+17$} & $4.69 * 1 e+17$ \\
\hline 4 & 5.8 & 2016/4/14 & 22:07:35 & 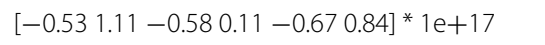 & $1.47 * 1 e+17$ \\
\hline 5 & 5.4 & 2016/4/16 & 01:44:06 & {$[-0.960 .460 .500 .79-1.672 .21] * 1 e+16$} & $3.15 * 1 e+16$ \\
\hline 6 & 5.4 & 2016/4/16 & 09:48:32 & 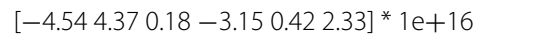 & $6.12 * 1 e+16$ \\
\hline 7 & 5.4 & 2016/4/16 & 16:02:01 & {$[-4.264 .55-0.29-3.16-1.461 .69] * 1 e+16$} & $6.22 * 1 e+16$ \\
\hline 8 & 5.1 & 2016/4/14 & 23:43:41 & {$\left[\begin{array}{lll}-0.48 & 1.49-1.01 & 0.41-0.842 .36\end{array}\right]^{*} 1 e+16$} & $2.91 * 1 e+16$ \\
\hline 9 & 5.0 & 2016/4/14 & $22: 38: 43$ & 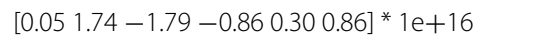 & $2.22 * 1 e+16$ \\
\hline 10 & 4.9 & 2016/4/16 & 02:04:11 & 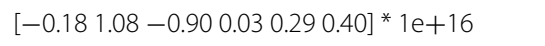 & $1.16 * 1 e+16$ \\
\hline 11 & 4.8 & $2016 / 4 / 16$ & $07: 23: 55$ & {$[-8.328 .36-0.045 .59-1.160 .43] * 1 e+15$} & $1.02 * 1 \mathrm{e}+16$ \\
\hline
\end{tabular}

\section{Appendix 2: Decomposition of non-DC MTs preserving $\mathrm{T}$-axis}

See Tables 5 and 6.

Table 5 Decomposition of non-DC MT of the $M_{J M A} 6.5$ foreshock from 2016/4/14 21:26:35 JST (event No. 1) and the decomposition by Eqs. (13) and (14) preserving MT $T$-axis

\begin{tabular}{lllccc}
\hline & Mechanism & S/D/R $\left(^{\circ}\right)$ & DC component (\%) & $\boldsymbol{M}_{\mathbf{0}}(\mathbf{N m})$ & $\frac{M_{0}}{M_{0}^{\text {sum }} \cdot 100 \%(\%)}$ \\
\hline Original non-DC MT & Strike-slip & $33 / 82 /-155$ & 64 & $1.84 * 1 \mathrm{e}+18$ & 100 \\
$\mathrm{MT}_{\text {major }}$ & Strike-slip & $33 / 82 /-155$ & 100 & $1.51 * 1 \mathrm{e}+18$ & 82 \\
$\mathrm{MT}_{\text {minor }}$ & Normal & $93 / 60 /-63$ & 100 & $0.33 * 1 \mathrm{e}+18$ & 18 \\
$\mathrm{MT}_{\text {sum }}$ & Strike-slip & $33 / 82 /-155$ & 64 & $1.84 * 1 \mathrm{e}+18$ & 100 \\
\hline
\end{tabular}

The original non-DC solution is listed with decomposed DC major and minor MTs and their sum $\mathbf{M T}_{\text {major }}+\mathbf{M T}_{\text {minor }}=\mathbf{M T}_{\text {sum }}$ S/D/R strike/dip/rake

Table 6 Same as Table 5, but for the $M_{\text {JMA }} 5.4$ aftershock from 2016/4/16 16:02:01 JST (event No. 7)

\begin{tabular}{|c|c|c|c|c|c|}
\hline & Mechanism & $S / D / R\left(^{\circ}\right)$ & DC component (\%) & $M_{0}(\mathrm{Nm})$ & $\frac{M_{0}}{M_{0}^{\text {sum }}} \cdot 100 \%(\%)$ \\
\hline Original non-DC MT & Normal & $68 / 63 /-95$ & 75 & $6.22 * 1 e+16$ & 100 \\
\hline$M T_{\text {major }}$ & Normal & $68 / 63 /-95$ & 100 & $5.44 * 1 e+16$ & 87 \\
\hline$M T_{\text {minor }}$ & Strike-slip & 297/81/16 & 100 & $0.79 * 1 e+16$ & 13 \\
\hline $\mathrm{MT}_{\text {sum }}$ & Normal & $68 / 63 /-95$ & 75 & $6.22 * 1 e+16$ & 100 \\
\hline
\end{tabular}

\section{Publisher's Note}

Springer Nature remains neutral with regard to jurisdictional claims in published maps and institutional affiliations.

Received: 4 July 2017 Accepted: 15 September 2017 Published online: 25 September 2017

\section{References}

Aki K, Richards P (2002) Quantitative seismology, 2nd edn. University Science Books, Sausalito. ISBN 0-935702-96-2

Asano K, Iwata T (2016) Source rupture processes of the foreshock and mainshock in the 2016 Kumamoto earthquake sequence estimated from the kinematic waveform inversion of strong data. Earth Planets Space 68:147. doi:10.1186/s40623-016-0519-9 
Bouchon M (1981) A simple method to calculate Green's functions for elastic layered media. Bull Seismol Soc Am 71:959-971

Dettmer J, Benavente R, Cummins PR, Sambridge M (2014) Trans-dimensional finite-fault inversion. Geophys J Int 199:735-751. doi:10.1093/gji/ggu280

Frohlich C (1994) Earthquakes with non-double-couple mechanisms. Science 264:804-809

Fukahata Y, Hashimoto M (2016) Simultaneous estimation of the dip angles and slip distribution on the faults of the 2016 Kumamoto earthquake through a weak nonlinear inversion of InSAR data. Earth Planets Space 68:204. doi:10.1186/s40623-016-0580-4

Goto H, Tsutsumi H, Toda S, Kumahara Y (2017) Geomorphic features of surface ruptures associated with the 2016 Kumamoto earthquake in and around the downtown of Kumamoto City, and implications on triggered slip along active faults. Earth Planets Space 69:26. doi:10.1186/ s40623-017-0603-9

Hallo M, Gallovič F (2016) Fast and cheap approximation of Green functions uncertainty for waveform-based earthquake source inversions. Geophys J Int 207:1012-1029. doi:10.1093/gji/ggw320

Hao J, Ji C, Yao Z (2017) Slip history of the 2016 M 7.0 Kumamoto earthquake: intraplate rupture in complex environment. Geophys Res Lett 44:743750. doi:10.1002/2016GL071543

Himematsu Y, Furuya M (2016) Fault source model for the 2016 Kumamoto earthquake sequence based on ALOS-2/PALSAR-2 pixel-offset data: evidence for dynamic slip partitioning. Earth Planets Space 68:169. doi:10.1186/s40623-016-0545-7

Jost ML, Herrmann RB (1989) A student's guide to and review of moment tensors. Seismol Res Lett 60:37-57

Kamata H, Kodama K (1994) Tectonics of an arc-arc junction: an example from Kyushu Island at the junction of the Southwest Japan Arc and the Ryukyu Arc. Tectonophysics 233(1-2):69-81. doi:10.1016/0040-1951 (94)90220-8

Kamata H, Kodama K (1999) Volcanic history and tectonics of the Southwest Japan Arc. Isl Arc 8:393-403. doi:10.1046/j.1440-1738.1999.00241.x

Kato A, Fukuda J, Nakagawa S, Kazushige O (2016) Foreshock migration preceding the $2016 \mathrm{Mw}$ 7.0 Kumamoto earthquake. Jpn Geophys Res Lett 43:8945-8953. doi:10.1002/2016GL070079

Kikuchi M, Kanamori H (1991) Inversion of complex body waves-III. Bull Seismol Soc Am 81(6):2335-2350

Kobayashi T (2017) Earthquake rupture properties of the 2016 Kumamoto earthquake foreshocks (Mj 6.5 and $\mathrm{Mj}$ 6.4) revealed by conventional and multiple-aperture InSAR. Earth Planets Space 69:7. doi:10.1186/ s40623-016-0594-y

Kobayashi H, Koketsu K, Miyake H (2017) Rupture processes of the 2016 Kumamoto earthquake sequence: causes for extreme ground motions. Geophys Res Lett. doi:10.1002/2017GL073857

Koketsu K, Miyake H, Suzuki H (2012) Japan integrated velocity structure model version 1. In: Proceedings of the 15th world conference on earthquake engineering, Lisbon, 24-28 Sept 2012

Kubo H, Suzuki W, Aoi S, Sekiguchi H (2016) Source rupture processes of the 2016 Kumamoto, Japan, earthquakes estimated from strong-motion waveforms. Earth Planets Space 68:161. doi:10.1186/s40623-016-0536-8

Kumahara Y, Goto H, Nakata T, Ishiguro S, Ishimura D, Ishiyama T, Okada S, Kagohara K, Kashihara S, Kaneda H, Sugito N, Suzuki Y, Takenami D, Tanaka K, Tanaka T, Tsutsumi H, Toda S, Hirouchi D, Matsuta N, Moriki H, Yoshida H, Watanabe M (2016) Distribution of surface rupture associated with the 2016 Kumamoto earthquake and its significance. Japan Geoscience Union Meeting 2016, MIS34-05
Lin A, Satsukawa T, Wang M, Mohammadi AZ, Fueta R, Nakajima F (2016) Coseismic rupturing stopped by Aso volcano during the 2016 Mw 7.1 Kumamoto earthquakes. Science 354:869-875

Matsumoto S, Nakao S, Ohkura T, Miyazaki M, Shimizu H, Abe Y, Inoue H, Nakamoto M, Yoshikawa S, Yamashita Y (2015) Spatial heterogeneities in tectonic stress in Kyushu, Japan and their relation to a major shear zone. Earth Planets Space 67:172. doi:10.1186/s40623-015-0342-8

Michael AJ (1984) Determination of stress from slip data: faults and folds. J Geophys Res 89:11517-11526

Okada A (1980) Quaternary faulting along the median tectonic line of southwest Japan. Mem Geol Soc Jpn 18:79-108

Shirahama Y, Yoshimi M, Awata Y, Maruyama T, Azuma T, Miyashita Y, Mori H, Imanishi K, Takeda N, Ochi T, Otusbo M, Asahina D, Miyakawa A (2016) Characteristics of the surface ruptures associated with the 2016 Kumamoto earthquake sequence, central Kyushu, Japan. Earth Planets Space 68:191. doi:10.1186/s40623-016-0559-1

Somerville P, Irikura K, Graves R, Sawada S, Wald D, Abrahamson N, Iwasaki Y, Kagawa T, Smith N, Kowada A (1999) Characterizing crustal earthquake slip models for the prediction of strong ground motion. Seismol Res Lett 70(1):59-80. doi:10.1785/gssrl.70.1.59

Tarantola A (2005) Inverse problem theory and methods for model parameter estimation. Society for Industrial and Applied Mathematics, Philadelphia. ISBN 0-89871-572-5

Toda S, Kaneda H, Okada S, Ishimura D, Mildon ZK (2016) Slip-partitioned surface ruptures for the Mw 7.0 16 April 2016 Kumamoto, Japan, earthquake. Earth Planets Space 68:188. doi:10.1186/s40623-016-0560-8

Vackár J, Gallovič F, Burjánek J, Zahradník J, Clinton J (2017) Bayesian ISOLA: new tool for automated centroid moment tensor inversion. Geophys J Int 210:693-705. doi:10.1093/gji/ggx158

Vavryčuk V (2014) Iterative joint inversion for stress and fault orientations from focal mechanisms. Geophys J Int 199:69-77. doi:10.1093/gji/ggu224

Wessel P, Smith WHF (1998) New, improved version of generic mapping tools released. EOS Trans Am Geophys Union 79:579

Yoshida K, Miyakoshi K, Somei K, Irikura K (2017) Source process of the 2016 Kumamoto earthquake (Mj7.3) inferred from kinematic inversion of strong-motion records. Earth Planets Space 69:64. doi:10.1186/ s40623-017-0649-8

Zahradník J, Plešinger A (2010) Toward understanding subtle instrumentation effects associated with weak seismic events in the near field. Bull Seismol Soc Am 100:59-73. doi:10.1785/0120090087

Zahradník J, Gallovič F, Sokos E, Serpetsidaki A, Tselentis GA (2008) Quick fault-plane identification by a geometrical method: application to the Mw 6.2 Leonidio Earthquake, 6 January 2008, Greece. Seismol Res Lett 79:653-662. doi:10.1785/gssrl.79.5.653

\section{Submit your manuscript to a SpringerOpen ${ }^{\odot}$ journal and benefit from:}

- Convenient online submission

- Rigorous peer review

- Open access: articles freely available online

- High visibility within the field

- Retaining the copyright to your article

Submit your next manuscript at $\boldsymbol{\nabla}$ springeropen.com 